Cochrane Database of Systematic Reviews

\title{
Transmyocardial laser revascularization versus medical therapy for refractory angina (Review)
}

Briones E, Lacalle JR, Marin-Leon I, Rueda JR

Briones E, Lacalle JR, Marin-Leon I, Rueda JR.

Transmyocardial laser revascularization versus medical therapy for refractory angina.

Cochrane Database of Systematic Reviews 2015, Issue 2. Art. No.: CD003712.

DOI: 10.1002/14651858.CD003712.pub3.

www.cochranelibrary.com 
TABLE OF CONTENTS

HEADER 1

ABSTRACT

PLAIN LANGUAGE SUMMARY

SUMMARY OF FINDINGS

BACKGROUND

OBJECTIVES

METHODS

RESULTS

Figure 1.

Figure 2.

Figure 3.

DISCUSSION

AUTHORS' CONCLUSIONS

ACKNOWLEDGEMENTS

REFERENCES

CHARACTERISTICS OF STUDIES

DATA AND ANALYSES

Analysis 1.1. Comparison 1 Transmyocardial laser revascularization versus medical treatment, Outcome 1 Angina reduction. .

Analysis 1.2. Comparison 1 Transmyocardial laser revascularization versus medical treatment, Outcome 2 Angina reduction (as-treated).

Analysis 1.3. Comparison 1 Transmyocardial laser revascularization versus medical treatment, Outcome 3 Overall mortality. ..

Analysis 1.4. Comparison 1 Transmyocardial laser revascularization versus medical treatment, Outcome 4 Overall mortality (astreated).

Analysis 1.5. Comparison 1 Transmyocardial laser revascularization versus medical treatment, Outcome 5 Early post-operative mortality.

Analysis 1.6. Comparison 1 Transmyocardial laser revascularization versus medical treatment, Outcome 6 Early post-operative mortality (as-treated).

Analysis 1.7. Comparison 1 Transmyocardial laser revascularization versus medical treatment, Outcome 7 Exercise tolerance. .

Analysis 1.8. Comparison 1 Transmyocardial laser revascularization versus medical treatment, Outcome 8 Seattle Angina Questionnaire - physical limitation.

Analysis 1.9. Comparison 1 Transmyocardial laser revascularization versus medical treatment, Outcome 9 Seattle Angina Questionnaire - angina frequency.

Analysis 1.10. Comparison 1 Transmyocardial laser revascularization versus medical treatment, Outcome 10 Seattle Angina Questionnaire - quality of life.

ADDITIONAL TABLES

APPENDICES

WHAT'S NEW

HISTORY

CONTRIBUTIONS OF AUTHORS

DECLARATIONS OF INTEREST

SOURCES OF SUPPORT

INDEX TERMS 
[Intervention Review]

\section{Transmyocardial laser revascularization versus medical therapy for refractory angina}

Eduardo Briones ${ }^{1}$, Juan Ramon Lacalle², Ignacio Marin-Leon³ , José-Ramón Rueda4

1Public Health Unit, Primary Care District. IBIS-CIBERESP, Sevilla, Spain. 2Preventive Medicine and Public Health, Universidad de Sevilla, Sevilla, Spain. ${ }^{3}$ Department of Internal Medicine, Hospital Universitario Virgen del Rocio, IBIS-CIBERESP, Sevilla, Spain. ${ }^{4}$ Department of Preventive Medicine and Public Health, University of the Basque Country, Leioa, Spain

Contact address: Eduardo Briones, Public Health Unit, Primary Care District. IBIS-CIBERESP, Avda Jerez s/n, Antiguo Hospital Militar, Sevilla, Sevilla, 41014, Spain. briones@cica.es.

Editorial group: Cochrane Heart Group.

Publication status and date: Stable (no update expected for reasons given in 'What's new'), published in Issue 4, 2016.

Citation: Briones E, Lacalle JR, Marin-Leon I, Rueda JR. Transmyocardial laser revascularization versus medical therapy for refractory angina. Cochrane Database of Systematic Reviews 2015, Issue 2. Art. No.: CD003712. DOI: 10.1002/14651858.CD003712.pub3.

Copyright @ 2016 The Cochrane Collaboration. Published by John Wiley \& Sons, Ltd.

\section{A B S T R A C T}

\section{Background}

This is an update of a review previously published in 2009. Chronic angina and advanced forms of coronary disease are increasingly more frequent. In spite of the improvement in the efficacy of available revascularization treatments, a subgroup of patients continue suffering from refractory angina. Transmyocardial laser revascularization (TMLR) has been proposed to improve the clinical situation of these patients.

\section{Objectives}

To assess the effects (both benefits and harms) of TMLR versus optimal medical treatment in people with refractory angina who are not candidates for percutaneous coronary angioplasty or coronary artery bypass graft, in alleviating angina severity, reducing mortality and improving ejection fraction.

\section{Search methods}

We searched the following resources up to June 2014: the Cochrane Central Register of Controlled Trials (CENTRAL), MEDLINE, EMBASE, the metaRegister of Controlled Trials database, ClinicalTrials.gov, and the WHO International Clinical Trials Registry. We applied no languages restrictions. We also checked reference lists of relevant papers.

\section{Selection criteria}

We selected studies if they fulfilled the following criteria: randomized controlled trials (RCTs) of TMLR, by thoracotomy, in patients with Canadian Cardiovascular Society or New York Heart Association angina grade III-IV who were excluded from other revascularization procedures.

\section{Data collection and analysis}

Three authors independently extracted data for each trial about the population and interventions compared and assessed the risk of bias of the studies, evaluating randomisation sequence generation, allocation concealment, blinding (of participants, personnel and outcome assessors), incomplete outcome data, selective outcome reporting, and other potential sources of bias.

\section{Main results}

From a total of 502 references, we retrieved 47 papers for more detailed evaluation. We selected 20 papers, reporting data from seven studies, which included 1137 participants, of which 559 were randomized to TMLR. Participants and professionals were not blinded, which 
suggests high risk of performance bias. Overall, $43.8 \%$ of participants in the treatment group decreased two angina classes, as compared with $14.8 \%$ in the control group: odds ratio (OR) 4.63, 95\% confidence interval (Cl) 3.43 to 6.25), and heterogeneity was present. Mortality by intention-to-treat analysis was similar in both groups at 30 days (4.0\% in the TMLR group and 3.5\% in the control group), and one year (12.2\% in the TMLR group and $11.9 \%$ in the control group). However, the 30 -day mortality as-treated was $6.8 \%$ in the TMLR group and $0.8 \%$ in the control group (pooled OR was $3.76,95 \% \mathrm{Cl} 1.63$ to 8.66 ), mainly due to a higher mortality in participants crossing from standard treatment to TMLR. The assessment of subjective outcomes, such as improvement in angina, was affected by a high risk of bias and this may explain the differences found. Other adverse events such as myocardial infarction, arrhythmias or heart failure, were not considered in this review, as they were not predefined outcomes in trials design and they show a high inconsistency across studies. No new trials on transmyocardial laser revascularization have been published in the last ten years and it is very unlikely that new research will be undertaken in this field.

\section{Authors' conclusions}

This review shows that risks associated with TMLR outweigh the potential clinical benefits. Subjective outcomes are subject to high risk of bias and no differences were found in survival, but a significant increase in postoperative mortality and other safety outcomes suggests that the procedure may pose unacceptable risks.

\section{PLAIN LANGUAGE SUMMARY}

\section{Transmyocardial laser revascularization compared to medical therapy for refractory angina}

This review examines the effectiveness and safety of a surgical intervention using a laser device directly on the heart surface for patients suffering from angina for whom other interventions are not suitable. This is an updated version of the original review published in 2009.

Patients with prolonged or recurrent chest pain due to heart disease have different treatment options, such as medication, catheter interventions, or coronary artery surgery. In spite of the optimal use of such treatments, an increasing number of patients progress to advanced disease, becoming less responsive to medical treatment, suffering from more severe symptoms, very limited exercise capacity and poor quality of life. Transmyocardial laser revascularization (TMLR) is a surgical intervention intended to re-establish blood flow in some areas of the heart, using a laser device directly on the heart surface, thereby relieving angina and improving symptoms.

Several studies have been carried out to determine the efficacy and safety of this intervention, but most had important methodological limitations and high risk of performance bias in relation to subjective outcomes such as angina pain. Overall, $43.8 \%$ of patients in the group treated with laser had their chest pain improved significantly, compared with $14.8 \%$ in the medication group. However, the evaluation of chest pain was performed without blinding (patients and doctors were aware of the intervention) and this may have biased the results. On the other hand, the risk of dying at one year was similar between the groups, but there is an excess risk of early mortality following the intervention in the laser group.

This updated review concludes that there is no evidence of clinical benefits after TMLR, but data on safety suggests that the procedure may pose unacceptable risks. The intervention is becoming obsolete and it is not expected that new research in this field would change this conclusion. 
SUMMARY OF FINDINGS

Summary of findings for the main comparison. Transmyocardial laser revascularization compared to medical treatment for refractory angina

Transmyocardial laser revascularization compared to medical treatment for refractory angina

Patient or population: patients with refractory angina

Settings: hospital care

Intervention: Transmyocardial laser revascularization

Comparison: Medical treatment

\begin{tabular}{|c|c|c|c|c|c|c|}
\hline \multirow[t]{3}{*}{ Outcomes } & \multicolumn{2}{|c|}{ Illustrative comparative risks* $(95 \% \mathrm{CI})$} & \multirow{3}{*}{$\begin{array}{l}\text { Relative ef- } \\
\text { fect } \\
(95 \% \mathrm{CI})\end{array}$} & \multirow{3}{*}{$\begin{array}{l}\text { No. of Partic- } \\
\text { ipants } \\
\text { (studies) }\end{array}$} & \multirow{3}{*}{$\begin{array}{l}\text { Quality of the } \\
\text { evidence } \\
\text { (GRADE) }\end{array}$} & \multirow[t]{3}{*}{ Comments } \\
\hline & \multirow{2}{*}{$\begin{array}{l}\text { Assumed risk } \\
\text { Medical treatment }\end{array}$} & \multirow{2}{*}{$\begin{array}{l}\text { Corresponding risk } \\
\begin{array}{l}\text { Transmyocardial laser revascu- } \\
\text { larization }\end{array}\end{array}$} & & & & \\
\hline & & & & & & \\
\hline \multirow{3}{*}{$\begin{array}{l}\text { Angina reduction } \\
\text { Decrease in two angina classes or } \\
\text { more }\end{array}$} & \multicolumn{2}{|l|}{ Study population } & \multirow{3}{*}{$\begin{array}{l}\text { OR 4.63 } \\
\text { (3.43 to } 6.25)\end{array}$} & \multirow{3}{*}{$\begin{array}{l}1051 \\
\text { (7 studies) }\end{array}$} & \multirow{3}{*}{$\begin{array}{l}\oplus \oplus \oplus \ominus \\
\text { low } 1,2\end{array}$} & \\
\hline & \multicolumn{2}{|l|}{ Moderate } & & & & \\
\hline & 32 per 1000 & $\begin{array}{l}\mathbf{1 3 3} \text { per } \mathbf{1 0 0 0} \\
\text { (102 to } 171)\end{array}$ & & & & \\
\hline \multirow{3}{*}{$\begin{array}{l}\text { Angina reduction - CCS score } \\
\text { Decrease in two angina classes or } \\
\text { more }\end{array}$} & \multicolumn{2}{|l|}{ Study population } & \multirow{3}{*}{$\begin{array}{l}\text { OR } 3.95 \\
\text { (2.9 to } 5.39)\end{array}$} & \multirow{3}{*}{$\begin{array}{l}923 \\
\text { (5 studies) }\end{array}$} & \multirow{3}{*}{$\begin{array}{l}\oplus \oplus \oplus \ominus \\
\text { low } 1,2\end{array}$} & \\
\hline & \multicolumn{2}{|l|}{ Moderate } & & & & \\
\hline & 89 per 1000 & $\begin{array}{l}\mathbf{2 7 8} \text { per } \mathbf{1 0 0 0} \\
\text { (221 to } 345)\end{array}$ & & & & \\
\hline \multirow{2}{*}{$\begin{array}{l}\text { Angina reduction - NYHA scale } \\
\text { Decrease in two angina classes or } \\
\text { more }\end{array}$} & \multicolumn{2}{|l|}{ Study population } & \multirow{2}{*}{$\begin{array}{l}\text { OR } 68.32 \\
(7.95 \text { to } \\
587.38)\end{array}$} & \multirow{2}{*}{$\begin{array}{l}128 \\
\text { (2 studies) }\end{array}$} & \multirow{2}{*}{$\begin{array}{l}\oplus \oplus \oplus \ominus \\
\text { moderate } 1\end{array}$} & \\
\hline & 0 per 1000 & $\begin{array}{l}0 \text { per } 1000 \\
(0 \text { to } 0)\end{array}$ & & & & \\
\hline
\end{tabular}




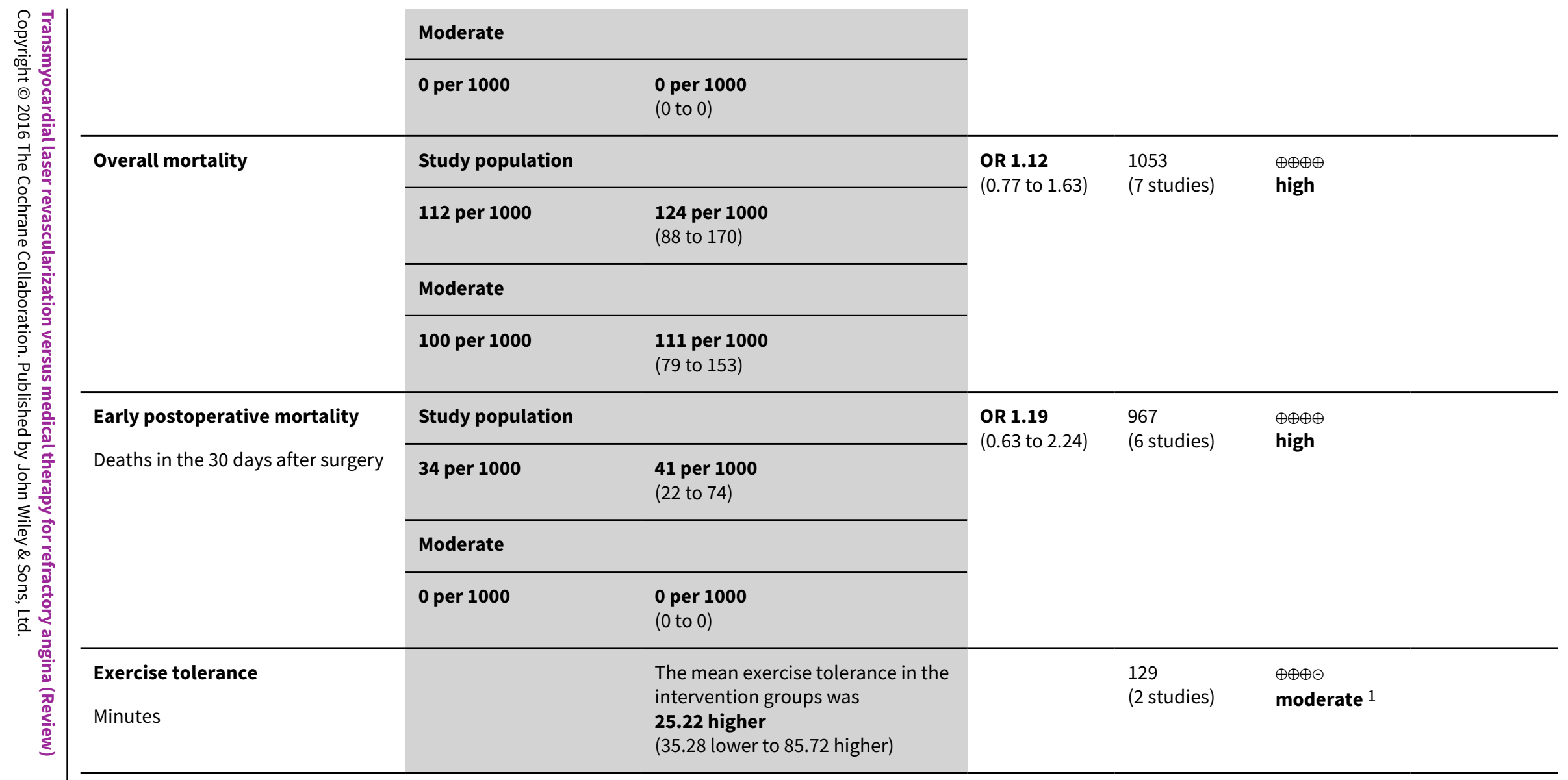

*The basis for the assumed risk (e.g. the median control group risk across studies) is provided in footnotes. The corresponding risk (and its $95 \%$ confidence interval) is based on the assumed risk in the comparison group and the relative effect of the intervention (and its $95 \% \mathrm{Cl}$ ).

CCS: Canadian Cardiovascular Society; Cl: Confidence interval; NYHA: New York Heart Association; OR: Odds ratio

GRADE Working Group grades of evidence

High quality: Further research is very unlikely to change our confidence in the estimate of effect.

Moderate quality: Further research is likely to have an important impact on our confidence in the estimate of effect and may change the estimate.

Low quality: Further research is very likely to have an important impact on our confidence in the estimate of effect and is likely to change the estimate.

Very low quality: We are very uncertain about the estimate.

1 Unblinded studies. Evaluation of subjective outcomes is likely to be affected by the lack of blindness. Randomization procedures unclear in all the studies, except one.

2 Angina reduction: High statistical heterogeneity: $I^{2}=83 \%$. $P<0.00001$. 


\section{B A C K G R O U N D}

\section{Description of the condition}

Ischaemic heart disease may become apparent and develop in very different ways. Acute and fatal presentations have attracted much attention, but chronic angina and advanced forms are becoming increasingly more relevant, probably associated with increasing patients' survival and improvements in medical and surgical treatments (Smolina 2012; Wijeysundera 2010). Most patients with less advanced stages respond adequately to treatment with antianginal medication, percutaneous coronary angioplasty (PTCA) with or without stenting, or coronary artery bypass surgery (CABG). In spite of the optimal use of such treatments, however, some patients with advanced disease present with frequent episodes of angina, limited exercise tolerance, and poor quality of life. Those patients are said to have refractory angina.

It has been estimated that 25,000 to 100,000 new patients may be diagnosed each year in the USA, while the overall prevalence could be between 300,000 and 900,000 patients (Manchanda 2011). Other studies have focused on a wider population suffering from severe chronic angina that may progress to refractory angina, producing estimates between $1 \%$ and $4 \%$ of the adult population in countries such as Canada and Spain (Borras 2012; Jolicoeur 2012; Qaseen 2012). The wide variability among studies is probably due to lack of a standardized definition, as the diagnosis of refractory angina depends on the lack of revascularization alternatives. Therefore, it may vary in different contexts according to the availability of revascularization technology, appropriateness of medical treatment and other interventions targeted to control anginal pain.

Recently, a more precise definition of refractory angina has been proposed, specifying the reason for revascularization unsuitability, such as microvascular dysfunction, epicardial stenosis or generalized lesions (Jolicoeur 2012). A multidisciplinary team should assess the therapeutic options, including intensifying medical treatment, cardiac rehabilitation and patient training and participation in symptoms control (McGuillion 2012). Other options that are available for these patients include spinal cord stimulation, enhanced external counter-pulsation and cognitive-behavioural self management interventions, but there is no good evidence of their effectiveness (Manchanda 2011; McGuillion 2012). Currently, TMLR is considered an option only in very specific cases by clinical practice guidelines (Fihn 2012).

\section{Description of the intervention}

Transmyocardial laser revascularization (TMLR) began to be used in 1983 in association with coronary artery bypass graft as a complementary technique (Smith 1995). Since then it has been considered as an alternative therapy for patients with refractory angina who were not amenable to conventional revascularization therapies. In these patients, the unsuitability for coronary artery bypass graft or percutaneous coronary angioplasty may be because of diffuse coronary atherosclerosis, distal stenoses, small coronary arteries, or the inability to undergo another coronary artery bypass graft or percutaneous coronary angioplasty (Burkhoff 2001). Its use spread quickly in the 1990s to several hospitals throughout the world, without sound evidence of its efficacy and safety; this led to the raising of difficult questions by clinicians and health service organizations (Prêtre 1999). A number of preliminary studies were enthusiastic about TMLR, showing a decrease in the severity of angina symptoms in most participants (Cooley 1996; Frazier 1995; Horvath 1996; Mirhoseini 1993). These results led to the spread of this technology throughout the world, although none of those studies was randomized (Caine 1998). Since 1999, several randomized controlled trials (RCTs) have been published, reporting contradictory results (Aaberge 2000; Burkhoff 1999; Frazier 1999; Jones 1999; Schofield 1999; van der Sloot 2004) and generating some debate on methodological issues (Downing 2000; Prêtre 1999). In particular, the issues spanned the appropriate selection of participants, possibility of cross-over (that is, allowing participants to shift from medical treatment to TMLR), inappropriate blinding of evaluators committed to assess angina, and other features of these studies (Saririan 2003; Sharples 1999; Williams 1999; Williams 2000).

\section{How the intervention might work}

After a thoracotomy, a laser device is placed on the epicardial surface of the left ventricle, creating 10 to 50 small channels from the epicardium to the endocardium (Mirhoseini 1982). The mechanism of action remains unknown. Initially, it was thought that the channels provided direct perfusion to the myocardium, but it has been found that the channels close a few days after the procedure. Other mechanisms, such as denervation or neo angiogenesis, have been proposed, but no clear evidence is available (Lange 1999; Prêtre 1999). The exact mechanism of action of TMLR still remains unknown. Several explanations have been proposed, including placebo effect, direct perfusion, denervation and angiogenesis (Schofield 1999).

\section{Why it is important to do this review}

This review is an update of a previously published review in The Cochrane Database of Systematic Reviews 2009, Issue 1 (Briones 2009).

This is an update of a review previously published in 2009. As the use of laser revascularization spread, several technology assessment reports (Briones 2003; MSAC 1999) and one systematic review have been published (Liao 2005). Due to contradictory results among RCTs on this topic, and the methodological problems found in some studies, it was felt that a more comprehensive systematic review was needed.

\section{O B JECTIVES}

This review aims to assess the effects (both benefits and harms) of TMLR versus optimal medical treatment in people with refractory angina who are not candidates for percutaneous coronary angioplasty or coronary artery bypass graft, in alleviating angina severity, reducing mortality and improving ejection fraction.

\section{METHODS}

\section{Criteria for considering studies for this review}

\section{Types of studies}

Eligible studies were RCTs with a parallel design and a minimum follow-up period of 12 months. 


\section{Types of participants}

We included studies of adults, 18 years or older, with angina classified as grade III or IV using the Canadian Cardiovascular Society (CCS) angina scale or New York Heart Association (NYHA) anginal class, and who were considered not to be candidates for revascularization using other conventional procedures (coronary artery bypass graft or percutaneous coronary angioplasty). We included studies with participants previously treated with a revascularization procedure, but receiving only the TMLR procedure during the study. We also included studies of participants with a diagnosis of acute coronary syndrome (or unstable angina).

\section{Types of interventions}

Transmyocardial laser revascularization performed by thoracotomy using a CO2, YAG-Holmyum or excimer laser, was compared with optimal medical treatment for angina. Studies comparing other laser revascularization techniques, such as percutaneous or adjuvant to other techniques (coronary artery bypass graft or percutaneous coronary angioplasty) were excluded from this review. This is justified by the foreseeable differences in effect, and in order to keep homogeneity. Effectiveness of other techniques is considered for comparison. purposes.

\section{Types of outcome measures}

\section{Primary outcomes}

- Improvement of severity of angina as measured by the Canadian Cardiovascular Society (CCS) angina scale or New York Heart Association (NYHA) anginal class.

- One-year mortality.

- Early postoperative mortality (deaths in the first month after surgery).

\section{Secondary outcomes}

- Improvement in exercise tolerance, as measured by the duration of a treadmill exercise test.

- Health-related quality of life using generic or specific instruments.

- Myocardial perfusion as assessed by thallium-201 photon emission computed tomography, technetium-99m-labelled sestamibi or a dipyridamol thallium stress test.

\section{Search methods for identification of studies}

\section{Electronic searches}

We searched the following electronic databases on 11 June 2014 without applying any language or date restrictions:

- Cochrane Central Register of Controlled Trials (CENTRAL), 2014, Issue 6.

- MEDLINE (PubMed) (1946 to Week 1, 2014).

- EMBASE (Ovid) (1980 to Week 20, 2014).

The search strategies for each database are reported in Appendix 1 (for the search in 2014) and Appendix 2 (for the search in 2007).

\section{Searching other resources}

We checked the reference lists of retrieved articles for additional trials.
We searched ongoing studies in the metaRegister of Controlled Trials database (mRCT) (www.controlled-trials.com), WHO International Clinical Trials Registry (ICTRP) (www.who.int/ictrp/ search/en/) and the National Library of Medicine database, ClinicalTrials.gov (clinicaltrials.gov). The searching terms were "revascularization AND laser". Other complementary sources were searched, such as reports published by health technology assessment agencies and other systematic reviews in DARE (accessible at www.york.ac.uk/inst/crd/crddatabases.htm).

We also scanned and checked the reference lists of some previous reviews (Briones 2003; Liao 2005) summarizing results on TMLR.

\section{Data collection and analysis}

\section{Selection of studies}

One author performed literature searches (JRR) in the databases and retrieved all papers fulfilling the inclusion criteria. In a second step, two review authors (EB and JRR) selected those trials to be included in this review, working independently and using the established inclusion criteria. In those articles in which the title or the abstract did not provide enough information to decide on rejection, the review authors obtained a full text copy to evaluate for inclusion. Cases of disagreement about the inclusion or exclusion were decided by consensus after consultation with a third review author (JRL).

\section{Data extraction and management}

A data extraction form was specifically designed for this review; it is available upon request from the authors. It was previously tested for comprehensiveness and reproducibility by using some of the papers located in the search phase. Two authors (EB and JRL) independently performed both quality assessment and data extraction, and disagreement was resolved by consensus. All reported outcomes were taken directly from the studies, and no recalculations were performed.

\section{Assessment of risk of bias in included studies}

For this update of the review, judgement of the risk of bias of the included studies has been assessed according to the methods and criteria defined in the last version of the Cochrane Handbook for Systematic Reviews of Interventions (Higgins 2011). Three authors ( $E B, J R L$ and JRR) independently assessed the risk of bias for each study for the following domains: sequence generation, allocation concealment, blinding of participants, personnel and outcome assessment, incomplete outcome data and selective reporting. Any disagreement was resolved by discussion and consensus.

\section{Measures of treatment effect}

\section{Dichotomous data}

We report data for dichotomous outcomes as odds ratios (ORs) with 95\% confidence intervals ( $\mathrm{Cls}$ ). In cases where an outcome with a zero event was noted, we estimated the Peto OR and $95 \% \mathrm{Cl}$.

\section{Continous data}

We used mean differences (i.e. control minus intervention group) for continuous outcomes, estimating differences in the means. 


\section{Dealing with missing data}

We analyzed all dichotomous data by intention-to-treat (ITT). The total number of participants randomly allocated to each treatment group was used to estimate the rate of response in order to compare the treatments. Several studies reported some of their results only graphically, without numerical information. In those cases, no imputation was performed and those results were not included in the analysis. We did not contact the authors of included studies with requests for additional data.

\section{Assessment of heterogeneity}

We tested pooled data for heterogeneity using Review Manager 5 software via a fixed-effect approach when no significant heterogeneity was found. If heterogeneity could not be explained, the data were pooled using a random effect approach and compared with fixed effect results. In sensitivity analyses, the effects of exclusion of trials for each methodological category were evaluated separately. We carried out a subgroup analysis comparing the results among different angina scales after noting that included studies used different angina severity scales (Canadian Cardiovascular Society (CCS) and New York Heart Association (NYHA)).

\section{RES U L T S}

\section{Description of studies}

\section{Results of the search}

The search retrieved 502 references in total: 91 in CENTRAL, 167 in EMBASE, 160 in MEDLINE, and 84 from three clinical trial registers. We excluded four hundred and fifty-five papers after reviewing the title and abstract (generally due to lack of suitability of study design or intervention or duplicate records). We retrieved papers for 47 references for more detailed evaluation and 20 (reporting on 7 studies) references were included in the review (Figure 1 ). 
Figure 1. Study flow diagram.

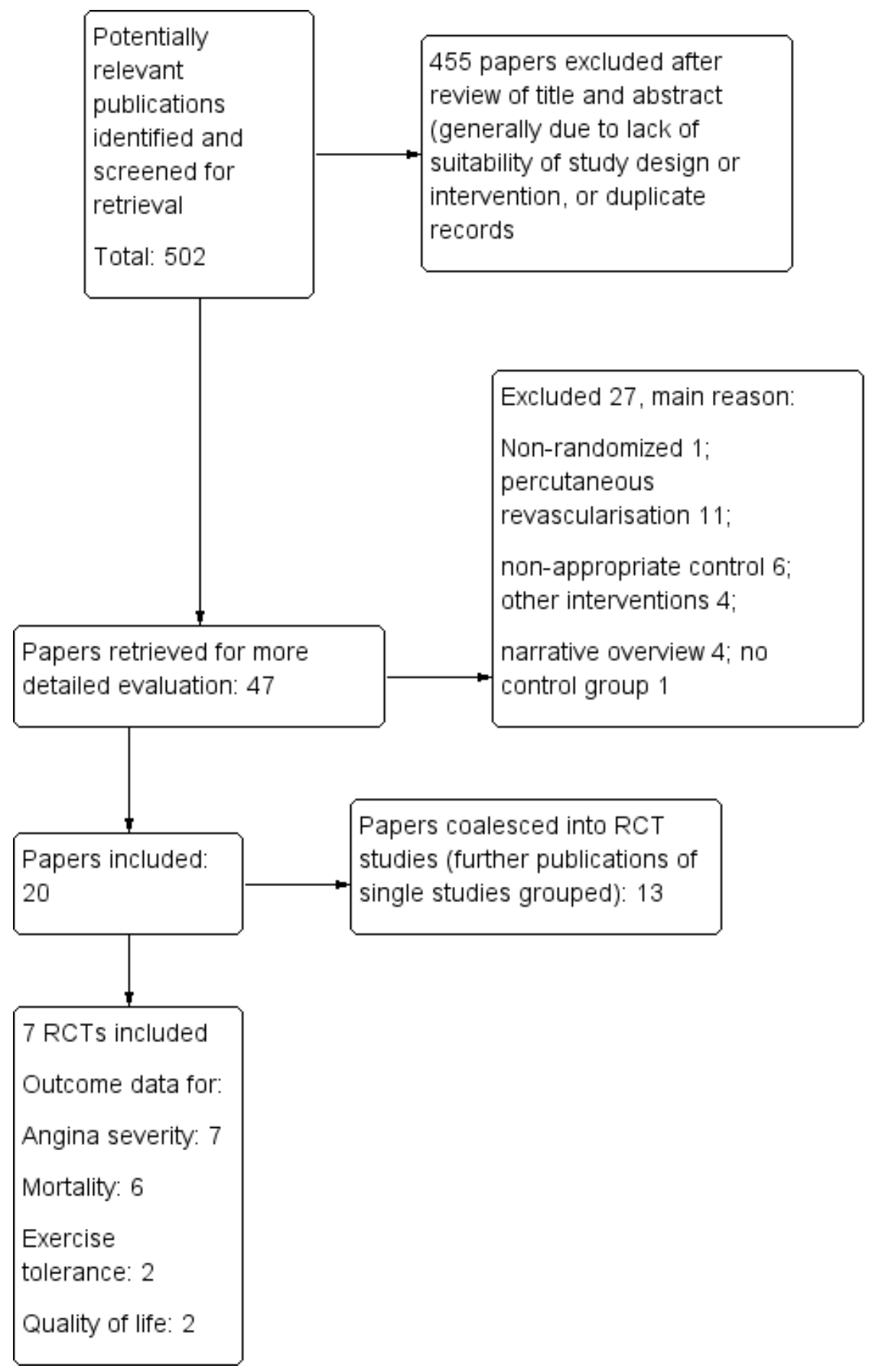

For this updated version we have not included any additional studies; none of the new studies published from June 2007 fulfilled the inclusion criteria of this review.

Searches in clinical trial registers located 84 references, but among them we did not find any ongoing or future RCT on the topic of this review.

\section{Included studies}

The included papers reported data from seven different studies. In total, 1137 participants were randomized; 559 participants were allocated to the TMLR group. All studies were published in peer reviewed journals. In three studies, the intervention was performed using the Holmiun YAG laser (Allen 1999; Burkhoff 1999; Jones 1999), the CO2 laser was used in three studies (Aaberge 2000; Frazier 1999; Schofield 1999), and the remaining study used the $\mathrm{XeCl}$ excimer laser (van der Sloot 2004). Technical details of the operative technique were considered to be similar among the studies. The studies showed differences in severity of angina at baseline; in two studies (Allen 1999; van der Sloot 2004) a great majority of participants were in Canadian Cardiovascular Society (CCS) class IV. In another two studies (Burkhoff 1999; Frazier 1999), 
the proportion of participants in class IV was around two-thirds, and in the remaining studies, the proportion was less than twothirds. Two studies (Aaberge 2000; van der Sloot 2004) measured the severity of angina using the New York Heart Association (NYHA) scale instead of the CCS score.

The following exclusion criteria for participants were compiled from the included studies: the need for continued use of intravenous antianginal medication; an inability to undergo the dipyridamole-thallium stress scintigraphy; a non-Q wave myocardial infarction within the two previous weeks or a Q-wave myocardial infarction within the three previous weeks; myocardial infarction in the previous weeks; the need for anticoagulant therapy; the presence of a ventricular mural thrombus; severe arrhythmias; decompensated congestive heart failure; patients with left main coronary artery lesions of greater than $70 \%$ without open bypasses to the anterior descending or circumflex arteries; cardiac transplant; lack of informed consent, life expectancy of less than 12 months because of a non-cardiac disorder, such as malignant disease, or those judged to be poor surgical candidates.

Primary outcomes of the selected studies were: exercise test in three studies (Aaberge 2000; Burkhoff 1999; Schofield 1999) and reduction in angina class in four studies (Allen 1999; Frazier 1999; Jones 1999; van der Sloot 2004). In all studies, angina relief was defined as a reduction by at least two classes in the CCS or NYHA score. In one study (Schofield 1999), chest pain was also assessed on an 11-point scale, with 0 as no pain and 10 as extreme pain. An exercise test was performed in most studies, though different protocols and outcome measures were used. Outcomes were measured at 12 months in a follow-up visit; all studies also reported some results at different points of time. One study (van der Sloot 2004) reported results at one month, and all studies except one (Aaberge 2000) reported results at six months. Three studies (Aaberge 2000; Allen 1999; Frazier 1999) have also published results of longer follow-up periods, ranging from three to five years.

Five studies (Allen 1999; Burkhoff 1999; Frazier 1999; Schofield 1999; van der Sloot 2004) reported results on quality of life as measured with these different scales: Duke Activity Index, Seattle Angina Questionnaire (SAQ), MOS-SF36 and EuroQol. Summary data on some variables, such as treadmill exercise mean time, are not reported; therefore, they are not included in the review. In one study (Schofield 1999), a cost-utility analysis was published.
Due to the different characteristics of participants included in the studies, a detailed description is given in the Characteristics of included studies tables; details of outcomes measured as reported in the papers are shown in Table 1.

\section{Excluded studies}

We excluded twenty-six studies. The reasons for exclusion are grouped in the following categories: combination with other surgical procedures (Allen 2000; Dowling 2003; Dziuk 2003; Frazier 2004; Loubani 2003); percutaneous transmyocardial laser revascularization (Dixon 2001; Leon 2005; Oesterle 1999; Oesterle 2000; Salem 2004; Salem 2005; Salem 2006; Stone 2002; Yang 2007); other treatments (Appelman 1996; Appelman 1998; Appelman 2000; Kniazeva 1994; McNab 2006; Vasil'ev 2003); non-comparative studies (Guleserian 2003; Milano 1997); and other reasons, such as three narrative overviews of RCTs (Horvath, 2000a; Horvath, 2000b; Horvath, 2002), or comparison of transmyocardial and percutaneous revascularization (Myers 2002).

\section{Risk of bias in included studies}

The risk of bias of the included studies is summarized in Figure 2 and Figure 3. More detailed information is presented in the 'Risk of bias' tables for each study. Sequence generation for randomisation was considered at low risk of bias in three studies (Burkhoff 1999; Frazier 1999; Schofield 1999) and unclear in four studies (Aaberge 2000; Allen 1999; Jones 1999; van der Sloot 2004). In three studies allocation concealment was considered unclear (Allen 1999; Jones 1999; van der Sloot 2004). Blinding of participants or healthcare personnel was not attempted in most of the studies. As with other surgical procedures, blinding of participants or healthcare providers is not an easy task, but it could be achieved using sham operations and similar procedures (Bienenfeld 1996). However, this may raise important ethical issues (Macklin 1999). On the other hand, only one study (Burkhoff 1999) performed a blinded assessment of a primary outcome, but the appropriateness of blinding was considered uncertain due to inappropriate reporting of data. It is considered that persons responsible for assessing outcomes should be unaware of the assigned intervention in order to avoid detection bias. This is not the case in the studies included, and therefore we considered that performance and detection bias were not adequately prevented in any of the studies. 
Figure 2. Risk of bias graph: review authors' judgements about each risk of bias item presented as percentages across all included studies.

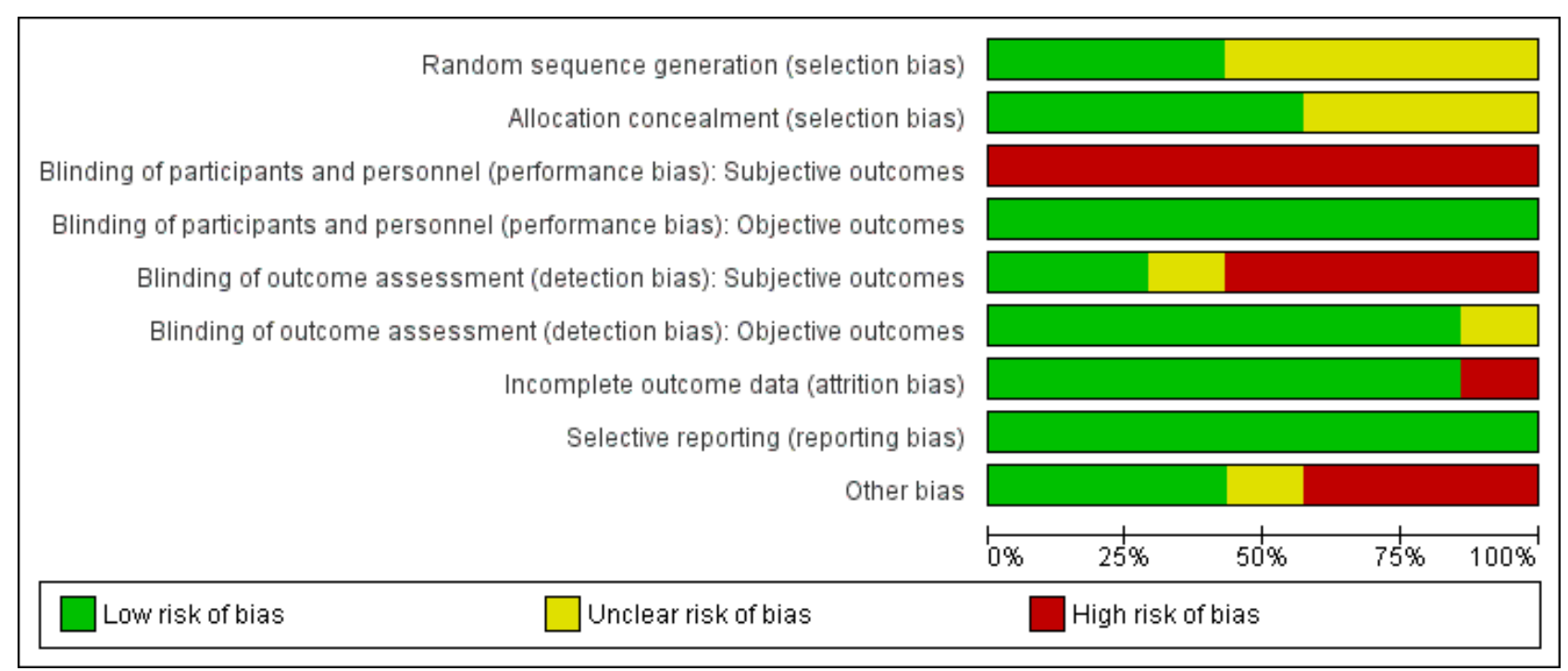


Figure 3. Risk of bias summary: review authors' judgements about each risk of bias item for each included study.

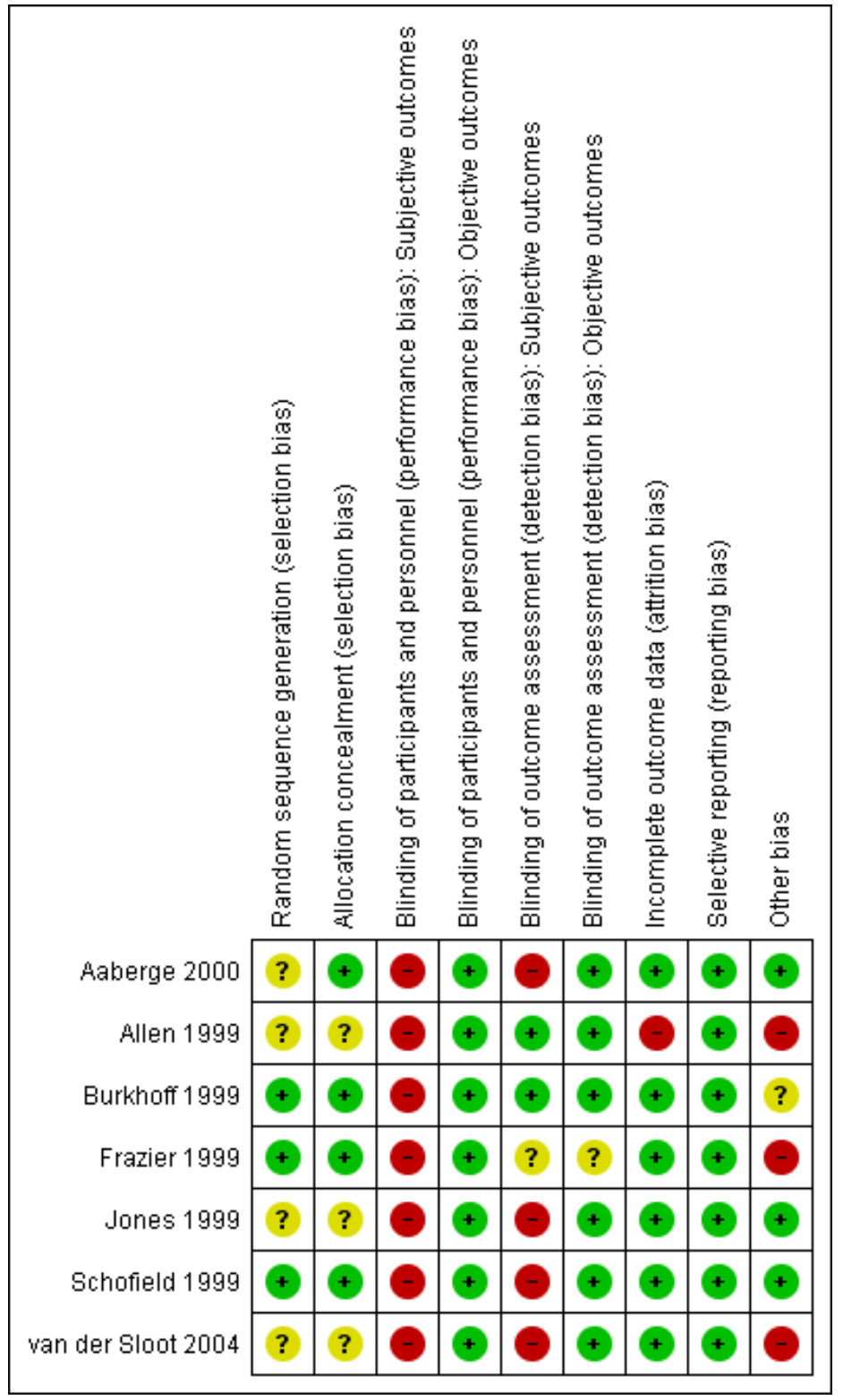

In two studies (Allen 1999; Frazier 1999) crossover was allowed, and participants allocated to the control group were offered to undergo TMLR. Intention-to-treat analysis was carried out in both cases. Attrition bias may be present in some studies due to a poor description on deaths and losses to follow-up. In order to have a complete view of the results, we used both intention-to-treat and as-treated results for the analysis of mortality variables.

Two studies (Aaberge 2000; van der Sloot 2004) reported no losses to follow-up and withdrawals. In two studies (Frazier 1999; Schofield 1999), the proportion was lower in the treatment group (4.4\% and $4.2 \%$ ) than in the medication group (10.9\% and $6.4 \%)$. In one study (Burkhoff 1999), the proportion in the revascularization group (9.8\%) was higher than in the control group (7.7\%). One study (Jones 1999) reported an overall proportion of $2.3 \%$, and one study (Allen 1999) did not report data.
Overall, the main source of bias in included studies was the lack of blinded assessment of subjective outcomes, particularly regarding angina. Secondary outcomes varied, and in most cases (including other measures of cardiac function or disease severity), they were of unknown reliability and no subgroup analysis was attempted.

\section{Effects of interventions}

See: Summary of findings for the main comparison Transmyocardial laser revascularization compared to medical treatment for refractory angina

The studies used different assumptions of primary endpoints. Some trials sought to demonstrate an alleviation of angina without increasing mortality, and others concentrated on functional capacity improvement, as shown by the exercise test. Details of each outcome reported are described below. 


\section{Angina relief}

Changes in angina class were reported in all seven studies; five used the CCS measure (Allen 1999; Burkhoff 1999; Frazier 1999; Jones 1999; Schofield 1999) and two used the NYHA measure (Aaberge 2000; van der Sloot 2004). Overall, $43.80 \%$ of participants in the treatment group decreased two angina classes as compared with $14.77 \%$ in the control group. All studies showed a significant reduction in at least two angina classes, with a wide variation of odds ratios (ORs) ranging from 1.71 (Allen 1999) to 79.22 (van der Sloot 2004) and a pooled OR of $4.63(95 \% \mathrm{Cl} 3.43$ to 6.25 ; Analysis 1.1). The test for heterogeneity was statistically significant $\left(\mathrm{Chi}^{2}=\right.$ $34.41, P<0.0001$ ). The source of heterogeneity may be due to one study, showing results with zero cases in the control group (Jones 1999). Studies using the CCS measure showed a lower odds ratio (OR 3.95, 95\% $\mathrm{Cl} 2.90$ to 5.39) than studies using the NYHA (OR 68.32, $95 \% \mathrm{Cl} 7.95$ to 587.38$)$.

We performed a subgroup analysis, separating the studies according to the angina scale used under the assumption that they may measure angina in different ways or measure different things. Studies that used the NYHA showed a higher pooled OR of 68.32 $(95 \% \mathrm{Cl} 7.95$ to 587.38$)$ and the test for heterogeneity was not statistically significant. On the contrary, studies using the CCS to test for heterogeneity were still significant and the pooled odds ratio was lower (OR 3.95, 95\% $\mathrm{Cl} 2.90$ to 5.39 ).

\section{Mortality}

Seven studies reported data on overall mortality, including perioperative and postoperative deaths (Aaberge 2000; Allen 1999; Burkhoff 1999; Frazier 1999; Jones 1999; Schofield 1999; van der Sloot 2004). This was done in order to provide a more detailed approach to the participants' survival. The overall mortality rate at one year using intention-to-treat analysis was $12.2 \%$ in the TMLR group and $11.9 \%$ in the control group. The pooled OR was 1.12 $(95 \% \mathrm{Cl} 0.77$ to 1.63 ; Analysis 1.3$)$ and using as-treated analysis was 1.22 (95\% Cl 0.81 to 1.83 ; Analysis 1.4), showing no statistically significant differences in both cases.

Six studies also reported data on early postoperative mortality (deaths after 30 days of intervention) (Aaberge 2000; Allen 1999; Burkhoff 1999; Frazier 1999; Schofield 1999; van der Sloot 2004). Overall, using intention-to-treat analysis, $4.01 \%$ of participants died in the TMLR group, ranging from $1.1 \%$ to $6.6 \%$, and $3.5 \%$ died in the control, showing no statistically significant difference; the pooled OR was 1.19 (95\% Cl 0.63 to 2.24; Analysis 1.5). However, the mortality rate of participants as-treated was $6.8 \%$ in the TMLR group and $0.8 \%$ in the control group, showing a statistically significant difference; the pooled OR was $3.76(95 \% \mathrm{Cl} 1.63$ to 8.66 ; Analysis 1.6). This difference is mainly due to the different mortality in crossover participants, showing the high risk of the procedure under certain circumstances.

\section{Exercise tolerance}

Although this outcome was measured in several studies in different ways, only two studies reported data suitable to be pooled (Aaberge 2000; van der Sloot 2004). The variable was the change in exercise duration from basal measurements to 12 months in both groups - treatment and control. The pooled weighted mean difference (WMD) showed an improved, but not statistically significant effect on TMLR participants (Analysis 1.7). Additionally, one study (Schofield 1999) reported differences between the groups, but raw data was only shown graphically and therefore not included in the pooled analysis.

\section{Quality of life}

Two studies (Frazier 1999; van der Sloot 2004) published data obtained by the Seattle Angina Questionnaire; they reported data in three domains. The results were pooled using the difference in the means at 12 months for each domain, assuming that basal values were similar. The physical component of the Seattle Angina Questionnaire was significantly improved among TMLR participants (WMD 13.10; Analysis 1.8), but differences in the other two domains (the frequency of angina (WMD -5.93; Analysis 1.9) and the perceived quality of life (WMD 2.19; Analysis 1.10)) were smaller and not statistically significant.

\section{Other outcome measurements}

We assessed other outcome measures in the studies, such as myocardial perfusion assessment (thallium-201, photon emission computed tomography, technetium-99m-labelled sestamibi, or a dipiridamol thallium stress test). However, they were not reported appropriately to be pooled and therefore not considered for the purpose of this review. We did not consider other related adverse events such as myocardial infarction, arrhythmias or heart failure in this review, as they were not predefined outcomes in trial designs, and they show a high inconsistency across studies.

\section{Long-term results}

Aaberge 2000 published results after a mean follow-up of five years. Mortality was not different between the two groups (24\% and $22 \%$; not significant). Angina improvement was still present after five years ( $3 \%$ versus $24 \%$; $P<0.001)$.

Allen 1999 also reported results after a mean follow-up of five years. Participants in the TMLR group experienced two or more CSS class improvements (42 of $48(88 \%))$ compared with participants in the control group (16 of $36(44 \%))$. Survival was higher in the TMLR group than in the control group $(65 \%$ versus $52 \%, P<0.05)$.

Frazier 1999 published follow-up data, but only on those participants who underwent TMLR, without publishing data on control participants. In this group, the improvement in angina after five years was very similar to that at one year, with $68 \%$ of participants showing a reduction of two or more in angina class. Also the results of the Seattle Angina Questionnaire showed a significant improvement at five years, compared with baseline, for all the components of this scale.

\section{DISCUSSION}

Transmyocardial laser revascularization (TMLR) has been subject to substantial controversy since the first studies were published, due to the contradictory results of efficacy and safety and the lack of explanation about the possible mechanisms of action. This updated systematic review provides a complete picture of the studies, including a new assessment of methodological quality and analysis of all outcomes published. No new trials have been published since previous publication, but risk of bias tables have been completely updated.

In original studies, a significant reduction in angina class was reported, but it was measured using unblinded methods, and a high risk of bias for the assessment of this and other 
subjective outcomes was found. No evidence of exercise capacity improvement was reported and, similarly, no improvement in survival at 12 months for TMLR participants. However, a statistically significant three-fold increase in 30-day postoperative mortality was found when participants were analyzed as-treated, although the intention-to-treat analysis showed no difference between groups.

All studies recruited participants with medically refractory angina not amenable to other revascularization techniques, who were randomized to TMLR versus medical management. In two trials, crossover was allowed and a substantial proportion of participants received the intervention after randomisation. Although we performed an intention-to-treat analysis, we considered it appropriate to analyse participants in the group that they were actually treated, in order to take into account the risks associated with the intervention. This approach showed a statistically significant higher risk of death in the treated group at 30 days, but not at the 12-month follow-up.

With regards to reduction of the degree of angina, the review shows that TMLR significantly reduced the angina score by at least two classes in the Canadian Cardiovascular Society (CCS) angina scale. Two out of seven of the original studies measured angina severity with the New York Heart Association (NYHA) scale. Although it is different from the CCS angina scale, a subgroup analysis yielded similar results. In this review we consider both scales as having equivalent clinical interpretation and weaknesses due to their subjective conditions.

In both cases, the main endpoint was the degree of improvement in angina (we considered a positive outcome a decrease in two classes at one year). TMLR treated participants had an absolute difference of $29 \%$ of positive outcome compared with the control group (43.8\% versus $14.8 \%$ ). It is relevant to note that angina is similar to pain as a subjective measure, and that it was assessed in an unmasked way to both participants and evaluators, and thereby conditioned a high risk of bias (Bienenfeld 1996). Blinding could be achieved using sham operations and similar procedures (Bienenfeld 1996), but it may raise important ethical issues (Macklin 1999). However, it was achieved in interventions performed percutaneously and it is always possible to blind evaluators of outcome measurements (Leon 2005).

With regard to exercise tolerance, the review did not show an improvement in effort capacity when pooling the two trials with available data. In the other three trials which observed improvement of exercise capacity, we could not combine the data. It is remarkable that exercise treadmill testing was measured in each trial in a different way and in some trials in a non-standardized way; this hindered the comparison of exercise performance. In addition, an unblinded assessment of the exercise test also hampered the credibility of the results.

Another interesting outcome is health related quality of life (HRQoL), where an improvement in physical well-being dimension was found in two studies as measured by the Seattle Angina Questionnaire. This result is consistent with the improvement in angina class scores, given that the reasons as to why the participants reported HRQoL deficits directly correlated to recurrent angina. This concordance between physical quality of life and angina improvement is also seen with other long-term followup studies of revascularization procedures (coronary artery bypass graft and percutaneous coronary intervention). No improvement was found in the other two domains (frequency of angina and perceived quality of life) from the available pooled data. Ideally, longitudinal assessment to evaluate changes over time in HRQoL outcomes with both general and disease-specific tools is desirable, but this was not available in the original studies.

A key issue is the lack of correlation of the subjective reduction of symptoms detected with a failure to demonstrate improvement in perfusion. The studies reveal that the overall number of sites with reversible perfusion defects did not significantly differ between the TMLR and medical management groups, even with an unblinded assessment in the trials. This raises the issue explaining the mechanism of how TMLR achieves its effects when a placebo effect could not be discarded.

A difficulty in the interpretation of the results is the diversity of inclusion criteria in the studies. Although some relevant variables such as the type of laser, severity of angina and concomitant medical therapy were not identical across trials, and formal tests for heterogeneity had a low power, the pool of studies is consistent in their relative effect sizes. Selection of participants and medical treatment are two clinical issues of interest. It was assumed in the studies that participants received optimal medical treatment. However, it has been acknowledged that half of the participants could have been stabilized with intensification of antianginal therapy alone (Nägele 1998). Some criticism has also been made concerning the inclusion criteria in trials with regards to the high proportion of participants not amenable for coronary artery bypass graft or to optimized medical treatment.

Also, the size and duration of the effect make it difficult to exclusively attribute it to unmasked assessment, but the available evidence is not strong enough to draw firm conclusions. Another suggested interpretation is that the long-term improvement of angina may be due to a differential selection of participants, where those with more severe angina would have a higher mortality after the intervention, thereby making the survivors appear symptomatically better. In a previous review, this effect was assessed in a sensitivity analysis by including all deaths as treatment failures. These results were not substantively different from the primary analysis, suggesting this does not explain the observed reductions in angina class after TMLR (Liao 2005).

The problem of non-adherence to the allocated treatment in randomized trials of cardiac surgery has been reported in other large scale studies (Peduzzi 1991). Alternative methods of analysis have been proposed: censoring crossovers, excluding them completely, transferring participants from one treatment group to another, or counting crossovers as if they had been allocated to the treatment ultimately received. Comparisons according to intention-to-treat is considered the most valid approach to compare treatments, producing unbiased estimates of effect measures. Notwithstanding, it is also interesting to get information about the harms directly associated with the surgical procedure, as deaths occurring in the days after the surgery, regardless the group originally assigned in the trials. When data were analyzed in this way, we observed a higher early mortality among those receiving revascularization, mainly due to the different mortality in crossover participants, showing the high risk of the procedure under certain circumstances. 
However, the one-year mortality odds ratio was similar both in the intention-to-treat and as-treated analysis, and therefore could be interpreted as revascularization having no effect in changing the prognosis of these participants.

It is interesting to note that other therapeutic alternatives not addressed in this review have also been attempted. In the last few years, various clinical trials have published efficacy tests of percutaneous laser myocardial revascularization versus a sham procedure (Leon 2005) and versus spinal cord stimulation (McNab 2006); however, no comparisons with TMLR have been found. Interestingly, one trial (Leon 2005) is the only known randomized controlled trial (RCT) designed to avoid the placebo effect that was carried out with double-blinding (comparison with a sham procedure and evaluator-blinded assessment of outcomes). No statistically significant difference was found in exercise duration or angina class.

For the interpretation of results, it is important to consider which assumptions are made concerning the ultimate goal of this treatment. For some authors, TMLR is aimed at alleviating the symptoms of myocardial ischaemia without compromising survival or cardiac function for end-stage participants with no other options available. Therefore, it can be considered an alternative procedure for alleviating angina, but with some potential risks, and the goal of the intervention may differ from what had been originally proposed. It could also be argued that other alternatives for this end-stage of disease have not been fully considered (Kim 2002). Also, other revascularization alternatives, such as minimally invasive surgery and drug eluting stents, have improved over time and have not been compared with TMLR. A key issue is to clarify the criteria for participant selection and information according to published factors related to increased perioperative mortality (Peterson 2003).

After publication of the first version of this review, another systematic review was published, including both transmyocardial and percutaneous laser revascularization (Campbell 2008). This review was the evidence base for two guidance documents, published by the National Institute for Health and Clinical Excelence (NICE) (Schofield 2010). With regards to TMLR, it included comparisons with other interventions, such as adjunct coronary artery bypass graft (two trials) and sympathectomy (one trial). Its findings and conclusions are fully concordant with this review and reinforce the placebo effect explanation for angina reduction. The review also highlights the importance of blinding the assessment of subjective outcomes, using sham operations or other procedures. It could be achieved in percutaneous interventions and no effect was found in improvement of angina (Campbell 2008; Leon 2005).

No new trials on TMLR have been published in the last ten years, and it is very unlikely that new research is being undertaken in this field. The procedure is becoming outdated and it is very unlikely that current conclusions will change.

Currently, different research alternatives for people suffering from refractory angina are being carried out. On the one hand, proposals for a better classification of this group of people have been made, leading to a more targeted treatment, including better coordination of multidisciplinary teams (Jolicoeur 2012). On the other hand, cell therapy has shown promising results in this and similar populations (Clifford 2012).

\section{AUTHORS' CONCLUSIONS}

\section{Implications for practice}

This updated review shows that risks associated with transmyocardial laser revascularization (TMLR) outweigh the potential clinical benefits. The observed improvement in angina is subject to high risk of bias and the effect disappears when assessments have been performed blindly in similar procedures. No differences were found in survival but a significant increase in postoperative mortality and other evidence on safety suggests that the procedure may pose unacceptable risks. Overall, the quality of the evidence is considered to be low, mainly due to the high risk of bias in the assessment of subjective outcomes in all studies.

On the other hand, TMLR is becoming an obsolete technology. No new trials on TMLR have been carried out in the last ten years and it is very unlikely that new research is being undertaken in this field and that current conclusions will change.

\section{Implications for research}

This review reinforces the idea that lack of blinding is one of the main pitfalls in studies assessing subjective outcomes, such as angina or quality of life. Future studies in the field of refractory angina should be better designed, with appropriate blinding of participants, healthcare providers and researchers, and a more precise definition of refractory angina.

Research on new technologies and improvements in service organization should be encouraged in this field, particularly those focusing on cell therapy and multidisciplinary teams' interventions. Methodological issues, such as those considered in this review should be taken into account.

\section{ACKNOWLEDGEMENTS}

This review is based partly on a research project funded by Instituto Carlos III - Fondo de Investigaciones Sanitarias, Ministry of Health (SPAIN) and research developed at the Andalusian Agency for Health Technology Assessment.

The Iberoamerican Cochrane Center has kindly provided methodological support and help with Review Manager software. 


\section{R E F E R E N C E S}

\section{References to studies included in this review}

Aaberge $\mathbf{2 0 0 0}$ \{published data only\}

Aaberge L, Askhus S, Nordstrand K, Abdelnoor M, Ihlen $\mathrm{H}$, Forfang K. Myocardial performance after transmyocardial revascularization with $\mathrm{CO}(2)$ laser. A dobutamine stress echocardiographic study. European Journal of Echocardiography 2001;2(3):187-96.

Aaberge L, Nordstrand K, Dragsund M, Saatvedt K, Endresen K, Golf $S$, et al. Transmyocardial revascularization with $\mathrm{CO} 2$ laser in patients with refractory angina pectoris. Clinical results from the Norwegian Randomized Trial. Journal of the American College of Cardiology 2000;35:1170-7.

Aaberge L, Rootwelt K, Blomhoff S, Saatvedt K, Abdelnoor M, Forfang K. Continued symptomatic improvement three to five years after transmyocardial laser revascularization with $\mathrm{CO}(2)$ laser: a late clinical follow-up of the Norwegian Randomized trial with transmyocardial laser revascularization. Journal of the American College of Cardiology 2002;39:1588-93.

* Aaberge L, Rootwelt K, Smith HJ, Nordstrand K, Forfang K. Effects of transmyocardial revascularization on myocardial perfusion and systolic function assessed by nuclear and magnetic resonance imaging methods. Scandinavian Cardiovascular Journal 2001;35:8-13.

\section{Allen 1999 \{published data only\}}

Allen KB, Dowling RD, Angell WW, Gangahar DM, Fudge TL, Richenbacher W, et al. Transmyocardial laser revascularization: 5 years follow-up of a prospective, randomized trial. Annals of Thoracic Surgery 2004;77:1228-34.

* Allen KB, Dowling RD, Fudge TL, Schoettle P, Sleinger SL, Gangahar DM, et al. Comparison of transmyocardial revascularization with medical therapy in patients with refractory angina. The New England Journal of Medicine 1999;341:1029-36.

\section{Burkhoff 1999 \{published data only\}}

Burkhoff D, Schmidt S, Schulman SP, Myers J, Resar J, Becker LC, et al. Transmyocardial laser revascularization compared with continued medical therapy for treatment of refractory angina pectoris: a prospective randomized trial. Lancet 1999;354:885-90.

\section{Frazier 1999 \{published data only\}}

* Frazier OH, March RJ, Horvath KA, Transmyocardial Carbon Dioxide Laser Revascularization Group. Transmyocardial revascularization with a carbon dioxide laser in patients with end-stage coronary artery disease. New England Journal of Medicine 1999;341:1021-8.

Hovarth KA, Aranki SF, Cohn LH, March RJ, Frazier OH, Kadipasaoglu KA, et al. Sustained angina relief 5 years after transmyocardial laser revascularization with a $\mathrm{CO}(2)$ laser. Circulation 2001;104(12 Suppl 1):181-4. trial. Seminars in Thoracic and Cardiovascular Surgery 1999;11(1):12-8.

Spertus JA, Jones PG, Coen M, Garg M, Bliven B, O'Keefe J, et al. Transmyocardial $\mathrm{CO} 2$ laser revascularization improves symptoms, function and quality of life: 12 -month results from a randomized controlled trial. American Journal of Medicine 2001;111:341-8.

\section{Jones 1999 \{published data only\}}

Jones JW, Schmidt SE, Richman BW, Miller CC, Sapire KJ, Burkhoff D, et al. Holmium: YAG laser transmyocardial revascularization relieves angina and improves functional status. Annals of Thoracic Surgery 1999;67:1596-1602.

\section{Schofield 1999 \{published data only\}}

Burns SM, Brown S, White CA, Tait S, Sharples L, Schofield PM. Quantitative analysis of myocardial perfusion changes with transmyocardial laser revascularization. American Journal of Cardiology 2001;87(7):861-7. [CENTRAL: CN-00372857]

Caine N, Tait S, Campbell H, Buxton M, Sharples LD, Schofield PM, et al. The UK trial of transmyocardial laser revascularisation (TMLR): cost effectiveness. 15th Annual Meeting of the International Society of Technology Assessment in Health Care; 1999 Jun 20-23. 1999:122.

Campbell HE, Tait S, Buxton MJ, Sharples LD, Caine N, Schofield PM, et al. A UK trial-based cost-utility analysis of transmyocardial laser revascularization compared to continued medical therapy for treatment of refractory angina pectoris. European Journal of Cardio-Thoracic Surgery 2001;20:312-8.

Campbell HE, Tait S, Sharples LD, Caine N, Gray TJ, Schofield PM, et al. Trial-based cost-utility comparison of percutaneous myocardial laser revascularisation and continued medical therapy for treatment of refractory angina pectoris. European Journal of Health Economics 2005;6(4):288-97. [CENTRAL: CN-00552367]

* Schofield PM, Sharples LD, Caine N, Burns S, Tait S, Wistow, T, et al. Transmyocardial laser revascularisation in patients with refractory angina: a randomised controlled trial. Lancet 1999;353:519-24.

Tait S, Caine N, Batas D, Sharples LD, Buxton M, Burns S, et al. The UK trial of transmyocardial laser revascularisation (TMLR): health related quality of life (HRQOL) [abstract]. 15th Annual Meeting of the International Society of Technology Assessment in Health Care; 1999 Jun 20-23. 1999:62. [CENTRAL: CN-00476490]

van der Sloot 2004 \{published data only\}

* Huikeshoven M, van der Sloot JAP, Tukkie R, van Gemert MJC, Tijssen JGP, Beek JF. Improved quality of life after XeCl excimer transmyocardial laser revascularization: results of a randomized trial. Lasers in Surgery and Medicine 2003;33:1-7. [DOI: 10.1002/ Ism.10189]

van der Sloot JAP, Huikeshoven M, Tukkie R, Verbene HJ, van der Meulen J, van Eck-Smit BLF, et al. Transmyocardial
March RJ. Transmyocardial laser revascularization with the $\mathrm{CO} 2$ laser: one year results of a randomized, controlled 
revascularization using an $\mathrm{XeCl}$ excimer laser: Results of a randomized trial. Annals of Thoracic Surgery 2004;78(3):875-81.

\section{References to studies excluded from this review}

Allen 2000 \{published data only\}

Allen KB, Dowling RD, DelRossi AJ, Realyvasques F, Lefrak EA, Pfeffer TA, et al. Transmyocardial laser revascularization combined with coronary artery bypass grafting: a multicenter, blinded, prospective, randomized, controlled trial. Journal of Thoracic and Cardiovascular Surgery 2000;119(3):540-9. [CENTRAL: CN-00275669]

\section{Appelman 1996 \{published data only\}}

Appelman YE, Piek JJ, Strikwerda S, Tijssen JG, de Feyter PJ, David GK, et al. Randomised trial of excimer laser angioplasty versus balloon angioplasty for treatment of obstructive coronary artery disease. Lancet 1996;347(8994):79-84. [CENTRAL: CN-00122402]

\section{Appelman 1998 \{published data only\}}

Appelman YE, Piek JJ, Redekop WK, de Feyter PJ, Koolen JJ, David GK, et al. Clinical events following excimer laser angioplasty or balloon angioplasty for complex coronary lesions: subanalysis of a randomised trial. Heart (British Cardiac Society) 1998;79(1):34-8. [CENTRAL: CN-00148577]

\section{Appelman 2000 \{published data only\}}

Appelman YE, Piek JJ, van der Wall EE, Redekop WK, van Royen EA, Fioretti PM, et al. Evaluation of the longterm functional outcome assessed by myocardial perfusion scintigraphy following excimer laser angioplasty compared to balloon angioplasty in longer coronary lesions. International Journal of Cardiac Imaging 2000;16(4):267-77. [CENTRAL: $\mathrm{CN}-00327681]$

\section{Dixon 2001 \{published data only\}}

Dixon SR, Schreiber TL, Rabah M, Lee DT, Kelco KL, O'Neill WW. Immediate effect of percutaneous myocardial laser revascularization on hemodynamics and left ventricular systolic function in severe angina pectoris. American Journal of Cardiology 2001;87(5):516-9. [CENTRAL: CN-00328342]

\section{Dowling 2003 \{published data only\}}

Dowling R, Thielmeier K, Ghaly A, Barber D, Boice T, Dine A. Improved pain control after cardiac surgery: results of a randomized, double-blind, clinical trial. Journal of Thoracic and Cardiovascular Surgery 2003;126(5):1271-8. [CENTRAL: CN-00459447]

\section{Dziuk 2003 \{published data only\}}

Dziuk M, el-Deeb H, Britton KE, Edmondson SJ, Piechota W, Cholewa M. Clinical outcome of patients after transmyocardial laser revascularization alone and combined with coronary artery bypass grafting [Kliniczna ocena efektu przezsercowej rewaskularyzacji laserowej polaczonej lub niepolaczonej z pomostowaniem aortalno-wiencowym]. Polski Merkuriusz Lekarski 2003;15(90):534-6. [CENTRAL: CN-00559730]

\section{Frazier 2004 \{published data only\}}

Frazier OH, Tuzun E, Eichstadt H, Boyce SW, Lansing AM, March RJ, et al. Transmyocardial laser revascularization as an adjunct to coronary artery bypass grafting: a randomized, multicenter study with 4-year follow-up. Texas Heart Institute Journal 2004;31(3):231-9. [CENTRAL: CN-00492808]

Guleserian 2003 \{published data only\}

Guleserian KJ, Maniar HS, Camillo CJ, Bailey MS, Damiano RJ, Moon MR. Quality of life and survival after transmyocardial laser revascularization with the holmium: YAG laser. Annals of Thoracic Surgery 2003;75(6):1842-7; discussion 1847-8. [CENTRAL: CN-00558872]

Horvath, 2000a \{published data only\}

Horvath KA. Results of clinical trials of transmyocardial laser revascularization versus medical management for end-stage coronary disease. Journal of Clinical Laser Medicine and Surgery 2000;18(5):247-52.

\section{Horvath, 2000b \{published data only\}}

Horvath KA. Transmyocardial laser revascularization in the treatment of myocardial ischemia. Journal of Cardiac Surgery 2000;15(4):271-7.

Horvath, 2002 \{published data only\}

Horvath KA. Results of prospective randomized controlled trials of transmyocardial laser revascularization. Heart Surgery Forum 2002;5(1):33-9.

Horvath, 2008 \{published data only\}

Horvath KA. Transmyocardial laser revascularization. Journal of Cardiac Surgery 2008;23(3):266-76.

Kniazeva 1994 \{published data only\}

Kniazeva TA, Nagapet'ian VK. The use of infrared laser radiation in the rehabilitation of IHD patients after the surgical revascularization of the myocardium [Ispol'zovanie infrakrasnogo lazernogo izlucheniia v reabilitatsii bol'nykh IBS posle khirurgicheskoi revaskuliarizatsii miokarda]. Voprosy Kurortologii, Fizioterapii, i Lechebnoi Fizicheskoi Kultury 1994;Nov-Dec(6):10-2. [CENTRAL: CN-00114479]

\section{Leon 2005 \{published data only\}}

Leon MB, Kornowski R, Downey WE, Weisz G, Baim DS, Bonow RO, et al. A blinded, randomized, placebo-controlled trial of percutaneous laser myocardial revascularization to improve angina symptoms in patients with severe coronary disease. Journal of the American College of Cardiology 2005;46(10):1812-9. [CENTRAL: CN-00531924]

Loubani 2003 \{published data only\}

Loubani M, Chin D, Leverment JN, Galiñanes M. Mid-term results of combined transmyocardial laser revascularization and coronary artery bypass. Annals of Thoracic Surgery 2003;76(4):1163-6. [CENTRAL: CN-00458111]

McNab 2006 \{published data only\}

McNab D, Khan SN, Sharples LD, Ryan JY, Freeman C, Caine N, et al. An open label, single-centre, randomized trial of spinal cord stimulation vs. percutaneous myocardial laser revascularization 
in patients with refractory angina pectoris: the SPiRiT trial. European Heart Journal 2006;27(9):1048-53. [CENTRAL: CN-00563544]

\section{Milano 1997 \{published data only\}}

Milano, Carlo AD. Transmyocardial revascularization with a holmium laser: preliminary results [Rivascolarizzazione transmiocardica con laser ad olmio: risultati preliminari]. Giornale Italiano Di Cardiologia 1997;27(10):1011-8. [CENTRAL: $\mathrm{CN}-00338266]$

\section{Myers 2002 \{published data only\}}

Myers J, Oesterle SN, Jones J, Burkhoff D. Do transmyocardial and percutaneous laser revascularization induce silent ischemia? An assessment by exercise testing. American Heart Journal 2002;143(6):1052-7.

\section{Oesterle 1999 \{published data only\}}

Oesterle SN. Laser percutaneous myocardial revascularization. American Journal of Cardiology 1999;83(4 A):46B-52B. [CENTRAL: CN-00413614]

\section{Oesterle 2000 \{published data only\}}

Oesterle SN, Sanborn TA, Ali N, Resar J, Ramee SR, Heuser R, et al. Percutaneous transmyocardial laser revascularisation for severe angina: the PACIFIC randomised trial. Potential Class Improvement From Intramyocardial Channels. Lancet 2000;356(9243):1705-10. [CENTRAL: CN-00331210]

\section{Salem 2004 \{published data only\}}

Salem M, Rotevatn S, Stavnes S, Brekke M, Vollset SE, Nordrehaug JE. Usefulness and safety of percutaneous myocardial laser revascularization for refractory angina pectoris. American Journal of Cardiology 2004;93(9):1086-91. [CENTRAL: CN-00469504]

\section{Salem 2005 \{published data only\}}

Salem M, Rotevatn S, Stavnes S, Brekke M, Pettersen R, Kuiper K, et al. Release of cardiac biochemical markers after percutaneous myocardial laser or sham procedures. International Journal of Cardiology 2005;104(2):144-51. [CENTRAL: CN-00552248]

\section{Salem 2006 \{published data only\}}

Salem M, Rotevatn S, Nordrehaug JE. Long-term results following percutaneous myocardial laser therapy. Coronary artery disease 2006;17(4):385-90. [CENTRAL: CN-00565446]

\section{Stone 2002 \{published data only\}}

Stone GW, Teirstein PS, Rubenstein R, Schmidt D, Whitlow PL, Kosinski EJ, et al. A prospective, multicenter, randomized trial of percutaneous transmyocardial laser revascularization in patients with nonrecognizable chronic total occlusions. Journal of the American College of Cardiology 2002;39(10):1581-7. [CENTRAL: CN-00380195]

\section{Vasil'ev 2003 \{published data only\}}

Vasil'ev AP, Strel'tsova NN, Senatorov luN. Efficacy of laser therapy in patients with ischemic heart disease [Effektivnost' lazeroterapii bol'nykh ishemicheskoi bolezn'iu serdtsa]. Voprosy
Kurortologii, Fizioterapii i Lechebnoi Fizicheskoi Kultury 2003;Jul$\operatorname{Aug}(4): 10-3$. [CENTRAL: CN-00457587]

\section{Yang 2007 \{published data only\}}

Yang SS, Li WM, Yin LL, Li Y, Fan Y, Han W, et al. Chronic effects of percutaneous transmyocardial laser revascularization in patients with refractory angina. Zhonghua Xin Xue Guan Bing Za Zhi 2007;35(1):51-4.

\section{Additional references}

\section{Bienenfeld 1996}

Bienenfeld L, Frishman W, Glasser SP. The placebo effect in cardiovascular disease. American Heart Journal 1996;132(6):1207-21.

\section{Borras 2012}

Borrás X, Garcia-Moll X, Gomez-Doblas JJ, Zapata A, Artigas R, AVANCE study researchers. Stable angina in Spain and its impact on quality of life. The AVANCE registry. Revista Espanol de Cardiologia (English Edition) 2012;65(8):734-41.

\section{Briones 2003}

Briones E, Rodriguez FJ. Eficacia, seguridad y eficiencia de la revascularización transmiocárdica con láser [Efficacy, security and efficiency of transmyocardial laser revascularization]. Madrid: Ministerio de Sanidad y Consumo, 2003. [ISBN 84-760-664-2]

\section{Burkhoff 2001}

Burkhoff D, Jones JW, Becker LC. Variability of myocardial perfusion defects by thallium 201 scintigraphy in patients with coronary artery disease not amenable to angioplasty or bypass surgery. Journal of the American College of Cardiology 2001;38:1033-9.

\section{Caine 1998}

Caine N, Schofield PM, Wallwork J, Sharples LD. British trial of transmyocardial revascularisation is continuing. $B M J$ 1998;316(7129):474-5. [CENTRAL: CN-00258677]

\section{Campbell 2008}

Campbell F, Messina J, FitzGerald P, Cantrell A, Czoski-Murray C. Systematic review of the efficacy and safety of transmyocardial and percutaneous laser revascularisation for refractory angina pectoris. Review body for interventional procedures (ScHARR). Shefield 2008.

\section{Clifford 2012}

Clifford DM, Fisher SA, Brunskill SJ, DoreeC, MathurA, Watt S, et al. Stem cell treatment for acute myocardial infarction. Cochrane Database of Systematic Reviews 2012, Issue 2. [DOI: 10.1002/14651858.CD006536.pub3]

\section{Cooley 1996}

Cooley DA, Frazier OH, Kadipasaoglu KA, Lindenmeir MH, Pehlivanoglu S, Kolff JW, et al. Transmyocardial laser revascularization: clinical experience with twelve-month follow-up. Journal of Thoracic and Cardiovascular Surgery 1996;111:791-7. 


\section{Downing 2000}

Downing SW. Transmyocardial laser revascularization. New England Journal of Medicine 2000;342:436-8.

\section{Fihn 2012}

Fihn SD, Gardin JM, Abrams J, Berra K, Blankenship JC, Dallas AP, et al. 2012 ACCF/AHA/ACP/AATS/PCNA/SCAI/STS Guideline for the diagnosis and management of patients with stable ischemic heart disease: a report of the American College of Cardiology Foundation/American Heart Association Task Force on Practice Guidelines, and the American College of Physicians, American Association for Thoracic Surgery, Preventive Cardiovascular Nurses Association, Society for Cardiovascular Angiography and Interventions, and Society of Thoracic Surgeons. Journal of the American College of Cardiology 2012;60(24):e44-e164.

\section{Frazier 1995}

Frazier OH, Cooley DA, Kadipasaoglu KA, Pehlivanoglu S, Lindenmeir MH, Barasch E, et al. Myocardial revascularization with laser: preliminary findings. Circulation 1995;92(Suppl II):58-65.

\section{Higgins 2011}

Higgins JPT, Altman DG, Sterne AC. Chapter 8: Assessing risk of bias in included studies. In: Higgins JPT, Green S (editors). Cochrane Handbook for Systematic Reviews of Interventions Version 5.1.0 [updated March 2011]. The Cochrane Collaboration, 2011. Available from www.cochranehandbook.org.

\section{Horvath 1996}

Horvath KA, Mannting F, Cummings N, Shernan SK, Cohn LH. Transmyocardial laser revascularization: operative techniques and clinical results at two years. Journal of Thoracic and Cardiovascular Surgery 1996;111:1047-53.

\section{Jolicoeur 2012}

Jolicoeur EM. Patients with coronary artery disease unsuitable for revascularization: definition, general principles, and a classification. Canadian Journal of Cardiology 2012;28:S50-S59.

\section{Kim 2002}

Kim MC, Kini A, Sharma SK. Refractory angina pectoris. Journal of the American College of Cardiology 2002;39:923-34.

\section{Lange 1999}

Lange RA, Hillis LD. Transmyocardial laser revascularization. New England Journal of Medicine 1999;341:1075-6.

\section{Liao 2005}

Liao L, Sarria-Santamera A, Matchar DB, Huntington AH Lin S, Whellan DJ, et al. Meta-analysis of survival and relief of angina pectoris after transmyocardial revascularization. American Journal of Cardiology 2005;95:1243-5. [DOI: 10.1016/ j.amjcard.2005.01.057]

\section{Macklin 1999}

Macklin R. The ethical problems with sham surgery in clinical research. New England Journal of Medicine 1999;341(13):992-6. [MEDLINE: 10498498]

\section{Manchanda 2011}

Manchanda A, Aggarwal A, Aggarwal N, Soran O. Management of refractory angina pectoris. Cardiology Journal 2011;18(4):343-51.

\section{McGuillion 2012}

McGillion M, Arthur HM, Cook A, Carroll SL, Victor JC, L'allier PL, et al. Management of patients with refractory angina: Canadian Cardiovascular Society/Canadian Pain Society joint guidelines. Canadian Journal of Cardiology 2012;28(2 Suppl):S20-41.

\section{Mirhoseini 1982}

Mirhoseini M, Muckerheide M, Cayton MM. Transventricular revascularization by laser. Lasers in Surgery and Medicine 1982;2:187-98.

\section{Mirhoseini 1993}

Mirhoseini M, Shelgikar S, Cayton MM. Transmyocardial laser revascularization: a review. Journal of Clinical Laser Medicine and Surgery 1993;11:15-9.

\section{MSAC 1999}

Medicare Service Advisory Committee. Transmyocardial laser revascularization. Canberra: Commonwealth of Australia, 1999.

\section{Nägele 1998}

Nägele H, Stubbe HM, Nienaber C, Rodiger W. Results of transmyocardial laser revascularization in non-revascularizable coronary artery disease after 3 years follow-up. European Heart Journal 1998;19(10):1525-30.

\section{Peduzzi 1991}

Peduzzi P, Detre K, Wittes J, Holford T. Intent-to-treat analysis and the problem of crossovers. An example from the Veterans Administration coronary bypass surgery study. Journal of Thoracic and Cardiovascular Surgery 1991;101:481-7.

\section{Peterson 2003}

Peterson ED, Kaul P, Kaczmarek RG, Hammill BG, Armstrong PW, Bridges $C R$, et al. From controlled trials to clinical practice: monitoring transmyocardial revascularization use and outcomes. Journal of the American College of Cardiology 2003;42(9):1611-6.

\section{Prêtre 1999}

Prêtre R, Turina MI. Laser to the heart: magic but costly, or only costly?. Lancet 1999;353:512-3.

\section{Qaseen 2012}

Qaseem A, Fihn SD, Dallas P, Williams S, Owens DK, Shekelle P, Clinical Guidelines Committee of the American College of Physicians. Management of stable ischemic heart disease: summary of a clinical practice guideline from the American College of Physicians/American College of Cardiology Foundation/American Heart Association/American Association for Thoracic Surgery/Preventive Cardiovascular Nurses Association/Society of Thoracic Surgeons. Annals of Internal Medicine 2012;157(10):735-43. 


\section{Saririan 2003}

Saririan M, Eisenberg MJ. Myocardial laser revascularization for the treatment of end-stage coronary artery disease. Journal of the American College of Cardiology 2003;41(2):173-83.

\section{Schofield 2010}

Schofield PM, McNab D. NICE evaluation of transmyocardial laser revascularisation for refractory angina revascularisation and percutaneous laser. Heart 2010;96:312-3.

\section{Sharples 1999}

Sharples L, Schofield P, Caine N, Wallwork J. Transmyocardial laser revascularisation in clinical practice. Lancet 1999;354:1994-5.

\section{Smith 1995}

Smith JA, Dunning JJ, Parry AJ, Large SR, Wallwork J. Transmyocardial laser revascularization. Journal of Cardiac Surgery 1995;10(5):569-72. [CENTRAL: CN-00120891]

\section{Smolina 2012}

Smolina K, Wright FL, Rayner M, Goldacre MJ. Determinants of the decline in mortality from acute myocardial infarction in England between 2002 and 2010: linked national database study. BMJ 2012;344:d8059.

\section{CHARACTERISTICS OF STUDIES}

Characteristics of included studies [ordered by study ID]

\section{Wijeysundera 2010}

Wijeysundera HC, Machado M, Farahati F, Wang X, Witteman W, van der Velde $\mathrm{G}$, et al. Association of temporal trends in risk factors and treatment uptake with coronary heart disease mortality, 1994-2005. JAMA 2010;303(18):1841-7.

\section{Williams 1999}

Williams SG, Wright DJ, Lindsay SJ, Tan LB. Transmyocardial laser revascularisation in clinical practice. Lancet 1999;354:1994-5.

\section{Williams 2000}

Williams SG, Wright DJ, Tan LB. Transmyocardial laser revascularization. New England Journal of Medicine 2000;342:436-8.

\section{References to other published versions of this review Briones 2009 \\ Briones E, Lacalle JR, Marin I. Transmyocardial laser revascularization versus medical therapy for refractory angina. Cochrane Database of Systematic Reviews 2009, Issue 1. [DOI: 10.1002/14651858.CD003712.pub2]}

* Indicates the major publication for the study

\section{Aaberge $\mathbf{2 0 0 0}$}

Methods RCT with parallel design. Single centre study

The National Hospital. Oslo. Norway. Duration: November 1995 - January 1998

Participants $\mathrm{N}$ : 100 randomized; 50 transmyocardial revascularization, 50 medical treatment

Mean age: 62.5 , range $41-75$. Male sex: $86 \%$. Prior coronary artery bypass grafting: $85 \%$. Prior percutaneous transluminal coronary angioplasty: $37 \%$

Inclusion criteria: participants with an earlier angiogram and refusing CABG or PTCA, NYHA angina class III or IV

Exclusion criteria: mild symptoms (angina class under III), age $>75$ years, confirmed non-reversible ischaemia, ejection fraction $<30 \%$, general poor health status, inability to undergo study tests or refusal to participate in a RCT

Interventions Transmyocardial revascularization and optimal medical treatment combined versus optimal medical treatment alone

Dioxide carbon laser. Peak power laser 800 W. Pulses synchronized with R wave in ECG. One channel per square centimetre

No crossover allowed

\section{Outcomes}

Primary: oxygen consumption and time to one millimetre of ST depression in exercise test

Secondary: morbidity and mortality during follow-up, improvement of angina class, other exercise test endpoints (time to chest pain, total exercise time and accumulated work) 
Follow-up period: 12 months.

Quality of life was measured using SF36. A follow-up of 3-5 years was reported in a separate paper

Trial Registration number: none available
Funding: supported by grants from the Norwegian Ministry of Health and Social Affairs
Declarations of interest: none presented

\section{Risk of bias}

\begin{tabular}{lll}
\hline Bias & Authors' judgement & Support for judgement \\
\hline $\begin{array}{l}\text { Random sequence genera- } \\
\text { tion (selection bias) }\end{array}$ & Unclear risk & $\begin{array}{l}\text { Mentioned as randomized but sequence generation procedure not described. } \\
\text { Quote: "patients were randomized 1:1 using block-randomization into two } \\
\text { comparable groups to achieve either continued optimal medical treatment } \\
\text { alone (MT group), or optimal medical treatment in combination with transmy- } \\
\text { ocardial revascularization with CO2-laser (TMR group)" }\end{array}$ \\
\hline $\begin{array}{ll}\text { Allocation concealment } \\
\text { (selection bias) }\end{array}$ & Low risk & $\begin{array}{l}\text { Quote: "After inclusion, each patient received an allocation number. Random- } \\
\text { ization was then performed by opening consecutively numbered sealed en- } \\
\text { velopes with allocation numbers and treatment inside. One patient initially } \\
\text { withdrew from the operation, but later changed his mind and was operated } \\
\text { on three months after randomisation; he has been followed up as patient who } \\
\text { has received the operation. All other patients were operated on within two } \\
\text { weeks after randomisation. Evaluation, randomisation and follow-up were } \\
\text { done at The National Hospital" }\end{array}$ \\
\hline
\end{tabular}

\begin{tabular}{|c|c|c|}
\hline $\begin{array}{l}\text { Blinding of participants } \\
\text { and personnel (perfor- } \\
\text { mance bias) }\end{array}$ & High risk & $\begin{array}{l}\text { Open study. Evaluation of subjective outcomes is likely to be affected by } \\
\text { the lack of blindness. Quote: "The investigation was designed as an open, } \\
\text { prospective, single center study" }\end{array}$ \\
\hline
\end{tabular}

Subjective outcomes

\begin{tabular}{ll}
\hline $\begin{array}{l}\text { Blinding of participants } \\
\text { and personnel (perfor- } \\
\text { mance bias) }\end{array}$ & $\begin{array}{l}\text { Open study. Evaluation of objective outcomes is not likely to be affected by the } \\
\text { lack of blindness }\end{array}$ \\
Objective outcomes &
\end{tabular}

\begin{tabular}{|c|c|c|}
\hline $\begin{array}{l}\text { Blinding of outcome as- } \\
\text { sessment (detection bias) } \\
\text { Subjective outcomes }\end{array}$ & High risk & $\begin{array}{l}\text { Open study. Evaluation of subjective outcomes is likely to be affected by the } \\
\text { lack of blindness }\end{array}$ \\
\hline $\begin{array}{l}\text { Blinding of outcome as- } \\
\text { sessment (detection bias) } \\
\text { Objective outcomes }\end{array}$ & Low risk & $\begin{array}{l}\text { Open study. Evaluation of objective outcomes is not likely to be affected by the } \\
\text { lack of blindness }\end{array}$ \\
\hline $\begin{array}{l}\text { Incomplete outcome data } \\
\text { (attrition bias) } \\
\text { All outcomes }\end{array}$ & Low risk & $\begin{array}{l}\text { No losses in the follow-up reported. Quote: "Follow-up of patients after three } \\
\text { and } 12 \text { months was complete. However, one patient in each group did not per- } \\
\text { form the exercise tests after } 12 \text { months: one because of a cerebral hemorrhage } \\
\text { and inability to perform tests and one for personal reasons" }\end{array}$ \\
\hline $\begin{array}{l}\text { Selective reporting (re- } \\
\text { porting bias) }\end{array}$ & Low risk & $\begin{array}{l}\text { Study protocol not available but published report included main outcomes of } \\
\text { interest. Quote: "Predefined primary end points were time to one millimeter } \\
\text { of ST segment depression and } \mathrm{MVO}_{2} \text {. Secondary end points were time to chest } \\
\text { pain, total exercise time and accumulated work" }\end{array}$ \\
\hline Other bias & Low risk & $\begin{array}{l}\text { The study appears to be free of other sources of bias. No significant differences } \\
\text { in baseline characteristics of patients between the treatment groups }\end{array}$ \\
\hline
\end{tabular}


Allen 1999

Methods RCT with parallel design. Multicentre study

18 centres. USA

Participants

$\mathrm{N}$ : 275 randomized; 132 transmyocardial revascularization, 143 medical treatment. 46 patients assigned to medical treatment only were withdrawn from the study and underwent transmyocardial laser revascularization under a parallel, FDA-approved protocol for patients who could not be weaned from intravenous antianginal medication

Mean age: 60 . Male sex: $75 \%$. Prior coronary artery bypass grafting: $86 \%$. Prior percutaneous transluminal coronary angioplasty: $48 \%$

Inclusion criteria: Refractory angina CCS class IV, not amenable to CABG or PTCA, reversible ischaemia determined by myocardial perfusion scanning, and ejection fraction $>25 \%$

Exclusion criteria: contraindication to general anaesthesia, severe chronic obstructive pulmonary disease, need of continued use of intravenous antianginal medication, inability to undergo dipyridamole-thallium stress scintigraphy, non Q-wave myocardial infarction in the previous two weeks, need of anticoagulant treatment, severe arrhythmias, and decompensated congestive heart failure

Interventions Transmyocardial laser revascularization plus continued medical therapy and continued medical treatment alone

20 W Holmiun laser. Pulses were not gated to the cardiac cycle. One channel per squared centimetre. Mean number of channels per patient: 39

Outcomes

Primary: Reduction in two or more CCS angina classes. Treatment failure: death, Q-wave myocardial infarction, two cardiac-related hospitalizations in 3 months, or three in 12 months, inability to withdrawn intravenous antianginal medication on two attempts in a 48-hour period. Change in myocardial perfusion, measured by dipyridamole-thallium stress testing

Secondary: Free of cardiac-related rehospitalization, survival free of cardiac events, use of cardiac medications, performance on an exercise treadmill tests, and quality of life score

Follow-up period: 12 months

Notes Trial Registration number: none available.

Funding: supported by a grant from Eclipse Surgical Technologies, Sunnyvale, California.

Declarations of interest: none presented.

\section{Risk of bias}

Bias Authors' judgement Support for judgement

Random sequence genera- Unclear risk tion (selection bias)
Mentioned as randomized but sequence generation procedure not described. Quote: "Randomization was performed by each center on a 1:1 basis, with a block size of six patients per center"

\begin{tabular}{ll}
\hline $\begin{array}{l}\text { Allocation concealment } \\
\text { (selection bias) }\end{array}$ & Unclear risk
\end{tabular}

\footnotetext{
(selection bias)
}

Blinding of participants and personnel (performance bias)

Subjective outcomes
High risk

Not reported. Probably unblinded. Evaluation of subjective outcomes is likely to be affected by the lack of blindness 
Allen 1999 (Continued)

Blinding of participants and personnel (perfor-

Low risk mance bias)

Objective outcomes
Not reported. Probably unblinded, but evaluation of objective outcomes is not likely to be affected by the lack of blindness

\begin{tabular}{|c|c|c|}
\hline $\begin{array}{l}\text { Blinding of outcome as- } \\
\text { sessment (detection bias) } \\
\text { Subjective outcomes }\end{array}$ & Low risk & $\begin{array}{l}\text { Blinded. Quote: "An independent laboratory (at the Cleveland Clinic Founda- } \\
\text { tion, Cleveland) conducted a masked assessment of angina and quality of life } \\
\text { at } 12 \text { months" }\end{array}$ \\
\hline
\end{tabular}

\author{
at 12 months"
}

Blinding of outcome as- Low risk sessment (detection bias)

Objective outcomes
Blinded. Quote: "Computerized quantification of ischemic changes, perfusion defects at rest, and delayed perfusion defects was performed in a masked manner by an independent laboratory."

Quote: "A blinded, independent data and safety monitoring committee monitored the study"

\section{Incomplete outcome data High risk} (attrition bias)

All outcomes
Primary end-point "angina": missing outcome data for more than one-third of the patients and no information provided about the reasons for it. 132 patients were initially allocated to TMLR and 143 to medical therapy alone but only 97 of them received that medical therapy alone given that 46 crossed to TMLR, which left overall 229 patients to follow-up. 33 patients died before one year, 21 in the TMLR group and 12 in the medical treatment group; that would leave 196 patients. For 12 months follow-up authors provided information for only 126 patients; not presenting data on 70 patients.

Quote: "Angina was evaluated at 3, 6, and 12 months in all surviving patients who were not crossed over to surgical treatment and who had reached the designated follow-up time (hereafter referred to as eligible patients): 213 of 221 patients (96\%) at 3 months, 172 of 183 (94\% per cent) at 6 months, and 126 of $136(93 \%)$ at 12 months."

Quote: "The Duke Activity Status Index was used to assess the quality of life. The index is based on a scale from 0 to 58 , with higher scores indicating greater functional capacity. Among the first 160 patients enrolled in the study, these assessments were performed at 12 months in 112 of 132 eligible patients (85\%)."

Quote: "Data on treatment failure were available at 12 months for 273 of 275 patients (99\%)"

Selective reporting (re- Low risk
porting bias)

Study protocol not available but published report included main outcomes of interest

Other bias High risk

Quote: "The demographic and clinical characteristics of the patients in the two treatment groups were similar." But baseline characteristics of compared groups were unbalanced in relation with a clinically relevant feature. Among the patients initially randomized to "medical treatment" 32\% could not be weaned from intravenous antianginal medication and underwent transmyocardial revascularization. If randomisation performed well, among the patients initially randomized to the laser group we would expected a similar percentage of around 32\% that made them directly eligible for TMLR.

Quote: "The improvement in angina in the medical-therapy group at 12 months reflects the reduction in the number of patients in this group as the sicker patients were withdrawn so that they could undergo transmyocardial revascularization under a separate protocol."

"Quote: "Forty-six patients (32 percent) initially assigned to receive medical therapy alone met the a priori criteria for treatment failure and could not be weaned from intravenous antianginal medication on two attempts over a period of 48 hours. They were withdrawn from the study and underwent trans- 
Allen 1999 (Continued)

myocardial revascularization under a parallel, FDA-approved protocol for patients who could not be weaned from intravenous antianginal medications. Thus, there were three groups of patients: those randomly assigned to undergo transmyocardial revascularization and to receive continued medical therapy (132 patients), those who received medical therapy alone throughout the study (97), and those randomly assigned to receive medical therapy alone who met the criteria for treatment failure and underwent transmyocardial revascularization as part of a separate protocol (46). The third group of patients is hereafter referred to as the crossover group."

Composite outcome measure "Treatment failure" includes many components and counts them as equivalent when they have different relevance for the patients: e.g. having "two cardiac-related hospitalizations in 3 months" counts the same as "death"

\section{Burkhoff 1999}

Methods $\quad$ RCT with parallel design. Multicentre study. "Atlantic study"

16 centres. USA

\section{Participants}
$\mathrm{N}$ : 182 randomized; 92 transmyocardial revascularization and continued medication, 90 continued medication alone

Mean age: 64 , range $36-78$. Male sex: $90 \%$. Prior coronary artery bypass grafting: $90 \%$. Prior percutaneous transluminal coronary angioplasty: $53 \%$

Inclusion criteria: CCS angina class III-IV, ejection fraction $>30 \%$, reversible perfusion defects on dypiridamolle-thallium stress test, with at least one region of protected myocardium, angiographically defined

Exclusions: myocardial infarction in the previous 3 months, admitted to hospital for unstable angina in the last 21 days, severe symptomatic heart failure, ventricular arrhythmias, cardiac transplant or judged to be poor surgical candidate

\begin{tabular}{ll}
\hline Interventions & Transmyocardial laser revascularization with continued medication and continued medical treatment \\
only & Holmium: YAG laser. One channel per square centimetre, with a median of 18 channels per patient
\end{tabular}

Holmium: YAG laser. One channel per square centimetre, with a median of 18 channels per patient

Outcomes Primary: change in exercise duration on a standard protocol

Secondary: angina, quality of life, and dipyridamolle-thallium stress test

Follow-up period: 12 months

$\begin{array}{ll}\text { Notes } & \text { Trial Registration number: none available } \\ & \text { Funding: supported by CardioGenesis Corporation, Sunnyvale CA, USA } \\ & \text { Declarations of interest: none presented }\end{array}$

\section{Risk of bias}

\begin{tabular}{lll}
\hline Bias & Authors' judgement & Support for judgement \\
\hline $\begin{array}{l}\text { Random sequence genera- } \\
\text { tion (selection bias) }\end{array}$ & Low risk & $\begin{array}{l}\text { Central randomisation. Sequence generation procedure not described. Quote: } \\
\text { "We used block randomisation according to site to achieve roughly equal dis- } \\
\text { tribution between groups at each site. Randomization was done by a central } \\
\text { coordinating centre by telephone. The co-ordinating centre confirmed eligi- }\end{array}$ \\
\end{tabular}


Burkhoff 1999 (Continued)

bility criteria before it provided a randomisation assignment. Six patients had minor deviations from protocol related to entry criteria but were included in analyses"

\begin{tabular}{lll}
\hline $\begin{array}{l}\text { Allocation concealment } \\
\text { (selection bias) }\end{array}$ & Low risk & Central randomisation \\
\hline
\end{tabular}

\begin{tabular}{|c|c|c|}
\hline $\begin{array}{l}\text { Blinding of participants } \\
\text { and personnel (perfor- } \\
\text { mance bias) }\end{array}$ & High risk & $\begin{array}{l}\text { Unblinded. Evaluation of subjective outcomes is likely to be affected by the } \\
\text { lack of blindness }\end{array}$ \\
\hline Subjective outcomes & & $\begin{array}{l}\text { Quote: "Angina improvement may be due to a placebo effect, a factor that can- } \\
\text { not be excluded in unmasked studies of angina relief" }\end{array}$ \\
\hline
\end{tabular}

$\begin{array}{ll}\begin{array}{l}\text { Blinding of participants } \\ \text { and personnel (perfor- }\end{array} & \text { Low risk }\end{array}$

mance bias)

Objective outcomes

Blinding of outcome as- Low risk sessment (detection bias) Subjective outcomes

Blinding of outcome as- Low risk

Low risk sessment (detection bias)

Objective outcomes
Blinded. Quote: "All endpoint data were assessed by central laboratory investigators who were unaware of treatment group"

\begin{tabular}{|c|c|c|}
\hline $\begin{array}{l}\text { Incomplete outcome data } \\
\text { (attrition bias) }\end{array}$ & Low risk & $\begin{array}{l}\text { Withdrawals and reasons clearly presented, balanced among comparison } \\
\text { groups and unlikely to bias the results. }\end{array}$ \\
\hline
\end{tabular}

All outcomes

Blinded. Quote: "All endpoint data were assessed by central laboratory investigators who were unaware of treatment group"

Quote: "16 patients withdrew from the study, nine in the TMLR group and seven in the medication-only group, all voluntarily. Although complete follow-up test results were not available for these patients, each one was contacted and was alive at 12 months. After deaths and withdrawals had been accounted for, 152 patients ( 78 in the TMLR group, 74 in the medication-only group) reached the end of the study and were assessed for angina. Of these, $74(95 \%)$ in the TMLR group and 67 (91\%) in the medication only group completed the exercise-tolerance test at 12 months"

\begin{tabular}{|c|c|c|}
\hline $\begin{array}{l}\text { Selective reporting (re- } \\
\text { porting bias) }\end{array}$ & Low risk & $\begin{array}{l}\text { Study protocol not available but published report included main outcomes of } \\
\text { interest }\end{array}$ \\
\hline \multirow[t]{2}{*}{ Other bias } & Unclear risk & $\begin{array}{l}\text { Some imbalance among baseline variables between compared groups. Quote: } \\
\text { "Age, sex, and baseline variables were similar in the two groups, although } \\
\text { there were higher frequencies of hypertension and hypercholesterolaemia and } \\
\text { higher disease perception score on the Seattle angina questionnaire in the } \\
\text { medication-only group." }\end{array}$ \\
\hline & & $\begin{array}{l}\text { In the methods sections authors stated: "Statistical analysis. The primary out- } \\
\text { come measure was the change in exercise duration on a standard protocol. } \\
\text { We designed the study to detect a difference of } 60 \mathrm{~s} \text {, which we took to be clin- } \\
\text { ically important, in the mean change from baseline in the TMLR group com- } \\
\text { pared with the medication-only group, with a power of } 80 \% \text { and a level of sig- } \\
\text { nificance of 0.05." But in the publication they do not present mean changes } \\
\text { but medians and ranges or IQR. Quote: "Results are presented as medians and } \\
\text { ranges or IQR." }\end{array}$ \\
\hline
\end{tabular}


Frazier 1999

Methods

RCT with parallel design. Multicenter study. "Transmyocardial Carbon Dioxide Laser Revascularization study"

12 centres. USA
$\mathrm{N}$ : 192 randomized; 91 transmyocardial revascularization, 101 medical treatment. 60 patients assigned to medical treatment, who could not be weaned from intravenous antianginal medication, crossedover to transmyocardial revascularization

Mean age: 61 . Male sex: $79 \%$. Prior coronary artery bypass grafting: $91 \%$. Prior percutaneous transluminal coronary angioplasty: $50 \%$

Inclusion criteria: CCS class III-IV angina, refractory to medical treatment, reversible ischaemia and coronary disease not amenable to CABG or PTCA

Excluded patients with ejection fraction under $20 \%$ or with a concurrent major disease

\begin{tabular}{ll}
\hline Interventions & $\begin{array}{l}\text { Transmyocardial laser revascularization and continued medical treatment. } \\
\text { Carbon dioxide laser. Peak power 850W. One channel per square centimetre }\end{array}$ \\
\hline Outcomes & Primary: Reduction of two or more angina classes \\
& Others: mortality, morbidity, quality of life, SPECT scan \\
& Follow-up period: 12 months \\
\hline Notes & Trial Registration number: none available \\
& Funding: PLC Medical Systems, Franklin, Mass \\
& Declarations of interest: none presented
\end{tabular}

\section{Risk of bias}

\begin{tabular}{|c|c|c|}
\hline Bias & Authors' judgement & Support for judgement \\
\hline $\begin{array}{l}\text { Random sequence genera- } \\
\text { tion (selection bias) }\end{array}$ & Low risk & $\begin{array}{l}\text { Central randomisation but sequence generation procedure not described. } \\
\text { Quote: "By means of randomisation at a central institution, patients were as- } \\
\text { signed, in a 1:1 ratio" }\end{array}$ \\
\hline $\begin{array}{l}\text { Allocation concealment } \\
\text { (selection bias) }\end{array}$ & Low risk & Central randomisation \\
\hline $\begin{array}{l}\text { Blinding of participants } \\
\text { and personnel (perfor- } \\
\text { mance bias) } \\
\text { Subjective outcomes }\end{array}$ & High risk & $\begin{array}{l}\text { Unblinded. Evaluation of subjective outcomes is likely to be affected by the } \\
\text { lack of blindness }\end{array}$ \\
\hline $\begin{array}{l}\text { Blinding of participants } \\
\text { and personnel (perfor- } \\
\text { mance bias) } \\
\text { Objective outcomes }\end{array}$ & Low risk & $\begin{array}{l}\text { Unblinded, but evaluation of objective outcomes is not likely to be affected by } \\
\text { the lack of blindness }\end{array}$ \\
\hline $\begin{array}{l}\text { Blinding of outcome as- } \\
\text { sessment (detection bias) } \\
\text { Subjective outcomes }\end{array}$ & Unclear risk & $\begin{array}{l}\text { Quote: "A blinded, independent assessment of angina was conducted in addi- } \\
\text { tion to the on-site evaluations." } \\
\text { However the results of that independent evaluation were not presented in the } \\
\text { publication. Authors only mentioned that: "For } 80 \text { percent of the patients, the } \\
\text { result of the independent assessment was within one CCS class of the result } \\
\text { of the on-site assessment, indicating consistency in the evaluations. When the }\end{array}$ \\
\hline
\end{tabular}




\begin{tabular}{|c|c|c|}
\hline $\begin{array}{l}\text { Blinding of outcome as- } \\
\text { sessment (detection bias) } \\
\text { Objective outcomes }\end{array}$ & Unclear risk & $\begin{array}{l}\text { Unblinded, but evaluation of objective outcomes is not likely to be affected by } \\
\text { the lack of blindness }\end{array}$ \\
\hline
\end{tabular}

\begin{tabular}{ll}
\hline $\begin{array}{l}\text { Incomplete outcome data } \\
\text { (attrition bias) }\end{array}$ & Low risk \\
All outcomes & $\begin{array}{l}6 \text { patients lost to follow-up, } 2 \text { in each group (laser, medical treatment and } \\
\text { cross-over groups) }\end{array}$
\end{tabular}

\begin{tabular}{|c|c|c|}
\hline $\begin{array}{l}\text { Selective reporting (re- } \\
\text { porting bias) }\end{array}$ & Low risk & $\begin{array}{l}\text { Study protocol not available but published report included main outcomes of } \\
\text { interest }\end{array}$ \\
\hline \multirow[t]{4}{*}{ Other bias } & High risk & $\begin{array}{l}60 \text { out of } 101 \text { of patients randomized to medical treatment crossed over to } \\
\text { laser treatment. }\end{array}$ \\
\hline & & $\begin{array}{l}\text { Quote: "Crossover from medical treatment to transmyocardial revascular- } \\
\text { ization was allowed if a patient had unstable angina that necessitated intra- } \\
\text { venous antianginal therapy for } 48 \text { hours or more in an intensive care unit. Af- } \\
\text { ter crossover, patients were followed for an additional } 12 \text { months, regardless } \\
\text { of how long they had been in the group assigned to medical treatment. These } \\
\text { patients were considered part of the medical-treatment group until crossover, } \\
\text { after which they were followed separately." }\end{array}$ \\
\hline & & $\begin{array}{l}\text { If randomisation performed well, among the patients initially randomized to } \\
\text { the laser group we would expected a similar percentage of around } 60 \% \text { with } \\
\text { unstable angina that made eligible directly for laser therapy. So clinical base- } \\
\text { line characteristics of compared groups were unbalanced in relation with a } \\
\text { clinical relevant feature, stability of the angina, circumstance that could bias } \\
\text { the evaluation of the impact of compared treatments. }\end{array}$ \\
\hline & & $\begin{array}{l}\text { Quote: "The option for crossover from the medical-treatment group to the } \\
\text { transmyocardial-revascularization group was the greatest limitation of this } \\
\text { study. Crossover was allowed as an incentive for patients assigned to maximal } \\
\text { medical therapy to remain in the study if medical therapy failed" }\end{array}$ \\
\hline
\end{tabular}

\begin{tabular}{ll}
\hline Methods & RCT with parallel design. Single centre study \\
& Missouri. USA \\
\hline Participants & N: 86 randomized; 43 transmyocardial revascularization, 43 medical treatment \\
& Mean age: 62. Male sex: \% not available. Prior coronary artery bypass grafting: $83 \%$. Prior percutaneous \\
transluminal coronary angioplasty: $50 \%$ & \\
& Inclusion criteria: CCS angina class 3-4, on maximal tolerated doses of at least two medications, and \\
& having areas of viable ischaemic myocardium by dypiridamole-thallium testing \\
& Exclusion criteria: patients with left main coronary artery lesions greater than $70 \%$ without open by- \\
passes to the anterior descending or circumflex arteries; patients with congestive heart failure; patients \\
with obstructive pulmonary disease when, in opinion of the principal investigator, it would affect exer- \\
cise testing
\end{tabular}

Interventions

Transmyocardial laser revascularization with continued medication and continued medical treatment only 
Follow-up period: 12 months

Notes

Trial Registration number: none available

Funding: Cardiogenesis Corporation

Declarations of interest: none presented

\section{Risk of bias}

\begin{tabular}{|c|c|c|}
\hline Bias & Authors' judgement & Support for judgement \\
\hline $\begin{array}{l}\text { Random sequence genera- } \\
\text { tion (selection bias) }\end{array}$ & Unclear risk & $\begin{array}{l}\text { Sequence generation procedure not described. Quote:"candidates at our pri- } \\
\text { mary single institution were randomized to } 2 \text { study groups by an independent } \\
\text { data management group" }\end{array}$ \\
\hline $\begin{array}{l}\text { Allocation concealment } \\
\text { (selection bias) }\end{array}$ & Unclear risk & Not reported. Probably not done \\
\hline $\begin{array}{l}\text { Blinding of participants } \\
\text { and personnel (perfor- } \\
\text { mance bias) } \\
\text { Subjective outcomes }\end{array}$ & High risk & $\begin{array}{l}\text { Unblinded. Evaluation of subjective outcomes is likely to be affected by the } \\
\text { lack of blindness }\end{array}$ \\
\hline $\begin{array}{l}\text { Blinding of participants } \\
\text { and personnel (perfor- } \\
\text { mance bias) } \\
\text { Objective outcomes }\end{array}$ & Low risk & $\begin{array}{l}\text { Unblinded, but evaluation of objective outcomes is not likely to be affected by } \\
\text { the lack of blindness }\end{array}$ \\
\hline $\begin{array}{l}\text { Blinding of outcome as- } \\
\text { sessment (detection bias) } \\
\text { Subjective outcomes }\end{array}$ & High risk & $\begin{array}{l}\text { Nothing mentioned about angina assessment, probably unblinded. Evaluation } \\
\text { of subjective outcomes is likely to be affected by the lack of blindness. } \\
\text { Blinded for exercise tests. Quote: "Those monitoring the exercise tests were } \\
\text { blinded to the group assignment of patients" }\end{array}$ \\
\hline $\begin{array}{l}\text { Blinding of outcome as- } \\
\text { sessment (detection bias) } \\
\text { Objective outcomes }\end{array}$ & Low risk & $\begin{array}{l}\text { Blinded. Quote: " Results, including ETTs, echocardiograms, and thallium } \\
\text { scans, were sent to a core laboratory, blind to the individual group assign- } \\
\text { ments, for final interpretation" }\end{array}$ \\
\hline $\begin{array}{l}\text { Incomplete outcome data } \\
\text { (attrition bias) } \\
\text { All outcomes }\end{array}$ & Low risk & Quote: "All but 2 living patients were followed for 12 months" \\
\hline $\begin{array}{l}\text { Selective reporting (re- } \\
\text { porting bias) }\end{array}$ & Low risk & $\begin{array}{l}\text { Study protocol not available but published report included main outcomes of } \\
\text { interest }\end{array}$ \\
\hline Other bias & Low risk & $\begin{array}{l}\text { The study appears to be free of other sources of bias. No significant differences } \\
\text { in baseline characteristics of patients between the treatment groups, except } \\
\text { for hypertension. Higher prevalence of hypertension on those randomized to } \\
\text { medical treatment ( } 83.7 \% \text { vs } 62.8 \% ; P=0.03) \text {, although authors examined it by } \\
\text { multivariate analysis and had no effect on endpoints }\end{array}$ \\
\hline
\end{tabular}


Schofield 1999

$\begin{array}{ll}\text { Methods } & \text { RCT with parallel design. Single centre study } \\ & \text { Cambridge. United Kingdom. Recruitment period: October } 1993 \text { - September } 1997\end{array}$

N: 188 randomized; 94 transmyocardial revascularization, 94 medical treatment.

Mean age: 60 . Male sex: $90 \%$. Prior coronary artery bypass grafting: $93 \%$. Prior percutaneous transluminal coronary angioplasty: $27 \%$

Inclusion criteria: reversible ischaemia on radionuclide myocardial perfusion scan

Exclussion criteria: unable to do treadmill exercise testing, ejection fraction $<30 \%$, were suitable for conventional revascularization, were on intravenous therapy to control angina, or life expectancy $<12$ months because of non-cardiac disorder

Transmyocardial laser revascularization plus normal medical treatment and medical management on-
ly.
Carbon dioxide laser. Peak power: $850 \mathrm{~W}$. Laser pulse gated on the R wave. One channel per square cen-
timetre. Median number of channels: 30 per patients

Outcomes

Primary: Duration of treadmill exercise test at 12 months. Reduction of two or more angina classes. Others: survival time, exercise test time, number of sites with reversible ischaemia.

Follow-up period: 12 months.

Trial Registration number: none available.
Funding: the Medical Research Council, service support for the research by the National Health Service
Executive Research and Development Programme, treatment costs by National Health Service authori-
ties, and a grant to obtain the laser equipment by BUPA Healthcare.
Declarations of interest: none presented

\section{Risk of bias}

\begin{tabular}{lll}
\hline Bias & Authors' judgement & Support for judgement \\
\hline $\begin{array}{l}\text { Random sequence genera- } \\
\text { tion (selection bias) }\end{array}$ & Low risk & $\begin{array}{l}\text { Quote: "A simple randomisation list was generated and held by the trial's sta- } \\
\text { tistician" }\end{array}$ \\
\hline $\begin{array}{l}\text { Allocation concealment } \\
\text { (selection bias) }\end{array}$ & Low risk & $\begin{array}{l}\text { Quote: "For practical reasons, randomisation was by consecutively numbered } \\
\text { opaque sealed envelopes which were opened by a research fellow after the } \\
\text { patient had given informed consent; this investigator was masked to the con- } \\
\text { tents before opening. Allocation was returned to the trial coordinator and the } \\
\text { number of patients assigned to each group was checked against the statisti- } \\
\text { cians' list" }\end{array}$ \\
\hline
\end{tabular}

\begin{tabular}{|c|c|c|}
\hline $\begin{array}{l}\text { Blinding of participants } \\
\text { and personnel (perfor- }\end{array}$ & High risk & $\begin{array}{l}\text { Unblinded. Evaluation of subjective outcomes is likely to be affected by the } \\
\text { lack of blindness }\end{array}$ \\
\hline
\end{tabular}

mance bias)

Subjective outcomes

\begin{tabular}{lll}
$\begin{array}{l}\text { Blinding of participants } \\
\text { and personnel (perfor- } \\
\text { mance bias) } \\
\text { Objective outcomes }\end{array}$ & Low risk & $\begin{array}{l}\text { Unblinded, but evaluation of objective outcomes is not likely to be affected by } \\
\text { the lack of blindness }\end{array}$ \\
\hline $\begin{array}{l}\text { Blinding of outcome as- } \\
\text { sessment (detection bias) } \\
\text { Subjective outcomes }\end{array}$ & High risk & $\begin{array}{l}\text { Nothing mentioned about angina and exercise test assessments, probably un- } \\
\text { blinded. Evaluation of subjective outcomes is likely to be affected by the lack } \\
\text { of blindness }\end{array}$
\end{tabular}


Schofield 1999 (Continued)

Blinding of outcome as- Low risk Evaluation of objective outcomes is not likely to be affected by the lack of sessment (detection bias)

Objective outcomes

\section{blindness.}

Quote: "All scans processed by 1 investigator blinded to patient identity and treatment assignment"

$\begin{array}{ll}\begin{array}{l}\text { Incomplete outcome data Low risk } \\ \text { (attrition bias) }\end{array} & \text { Number of withdrawals and reasons detailed in the report. Analyzed at one } \\ \text { All outcomes } & \text { year for primary endpoint: } 83 \text { out of } 94 \text { assigned to medical treatment only and } \\ & 77 \text { out of } 94 \text { for the laser group. Quote: "One TMLR patient, with a history of al- } \\ & \text { cohol abuse, was lost to follow-up. Five medical-management patients with- } \\ \text { drew soon after recruitment because they were unhappy about their treat- } & \text { ment allocation. The remaining four non-attenders (three TMLR, one medical } \\ \text { management) were unwell or had personal problems or commitments" }\end{array}$

\begin{tabular}{lll}
\hline $\begin{array}{l}\text { Selective reporting (re- } \\
\text { porting bias) }\end{array}$ & Low risk & $\begin{array}{l}\text { Study protocol not available but published report included main outcomes of } \\
\text { interest }\end{array}$ \\
\hline Other bias & Low risk & $\begin{array}{l}\text { The study appears to be free of other sources of bias. No significant differences } \\
\text { in baseline characteristics of patients between the treatment groups }\end{array}$ \\
\hline
\end{tabular}

van der Sloot 2004

\begin{tabular}{|c|c|}
\hline Methods & $\begin{array}{l}\text { RCT with parallel design. Single centre study } \\
\text { Amsterdam, The Netherlands }\end{array}$ \\
\hline \multirow[t]{4}{*}{ Participants } & $\begin{array}{l}\mathrm{N}: 30 \text { randomized; } 15 \text { transmyocardial revascularization with continued maximal medication, } 15 \text { med- } \\
\text { ical treatment only }\end{array}$ \\
\hline & $\begin{array}{l}\text { Mean age: } 61 \text {. Male sex: } 94 \% \text {. Prior coronary artery bypass grafting: } 96 \% \text {. Prior percutaneous translumi- } \\
\text { nal coronary angioplasty: } 22 \%\end{array}$ \\
\hline & $\begin{array}{l}\text { Inclusion criteria: angina NYHA class 3-4, refractory to conventional treatments and with detectable re- } \\
\text { versible myocardial ischaemia }\end{array}$ \\
\hline & Exclusion criteria: not reported \\
\hline Interventions & $\begin{array}{l}\text { Transmyocardial laser revascularization with continued maximal medication and medical treatment } \\
\text { only. } \\
\text { XeCl excimer laser with wave length of } 308 \mathrm{~nm} \text {. One channel per square centimetre. Laser pulses were } \\
\text { triggered } 110-120 \text { milliseconds after the R wave }\end{array}$ \\
\hline \multirow[t]{2}{*}{ Outcomes } & $\begin{array}{l}\text { Primary: Angina score, myocardial perfusion and function, exercise tolerance, medication, major car- } \\
\text { diac events and quality of life measures }\end{array}$ \\
\hline & Follow-up period: 12 months \\
\hline \multirow[t]{3}{*}{ Notes } & Trial Registration number: none available. \\
\hline & $\begin{array}{l}\text { Funding: The Dutch Heart Foundation. Contract grant number: nr. } 97-196 \text {. Quote: "This study was not } \\
\text { sponsored by the industry; however, we express our genuine gratitude to Udo Roslan (1997-1998 work- } \\
\text { ing at Vascular Therapies, a division of the United States Surgical Co, Elancourt, France) who made it } \\
\text { possible to begin this trial by guaranteeing financial support, if necessary." }\end{array}$ \\
\hline & Declarations of interest: none presented \\
\hline
\end{tabular}

\section{Risk of bias}


van der Sloot 2004 (Continued)

\section{Bias Authors' judgement Support for judgement}

Random sequence genera- Unclear risk tion (selection bias)

Sequence generation procedure not described. Quote: "This study was designed as a randomized single-center trial consisting of 30 patients. When 2 subsequent patients met the criteria they were included as a pair, randomized between excimer TMLR and continued maximal medication, and then followed simultaneously for 1 year. At randomisation patients assigned to continued maximal medication were offered to undergo TMLR after 1 year follow-up (no earlier)"

Allocation concealment Unclear risk Not reported. Probably not done

(selection bias)

Blinding of participants and personnel (perfor-

High risk

Unblinded. Evaluation of subjective outcomes is likely to be affected by the lack of blindness

mance bias)

Subjective outcomes

Blinding of participants Low risk
and personnel (perfor-
mance bias)
Objective outcomes

Unblinded, but evaluation of objective outcomes is not likely to be affected by the lack of blindness

Objective outcomes

Blinding of outcome as-

High risk

sessment (detection bias)

Subjective outcomes

\section{Blinding of outcome as- Low risk} sessment (detection bias)

Objective outcomes

Incomplete outcome data Low risk (attrition bias)

All outcomes
Nothing mentioned about it, probably unblinded. Evaluation of subjective outcomes is likely to be affected by the lack of blindness
Nothing mentioned about it, probably unblinded, but evaluation of objective outcomes is not likely to be affected by the lack of blindness

Quotes: "No patients were lost to follow-up. No data were missing at base line and at 12 months." "In both groups, missing QOL scores were substituted using linear interpolation, except when the 1 month FU was missing in the TMLR group. Then, the average (TMLR) group changes were used to calculate substitutes for the missing values. In case of missing data due to mortality, the last observations obtained before death were used as input for the remaining FU moments ('last observation carried forward')"

Selective reporting (re- Low risk Study protocol not available but published reports included main outcomes of porting bias) interest

Other bias

High risk

Quote: "As mentioned above, there are two important points in this study which may be considered limitations, as they could have created bias in the $\mathrm{QOL}$ results. The first limitation is the assessment of baseline $\mathrm{QOL}$ scores after randomisation. This may have created a positive baseline bias in the treatment group as well as a negative bias in the control group. The latter could also play a role as a consequence of the study design (i.e., non-blinded).

Cross-over offered to the patients allocated to medical treatment. Quote: "The second limitation which could have introduced a bias is the fact that at baseline, patients randomized to the control group were offered treatment after they had completed their 1 year FU. This may have introduced a positive anticipation bias, especially towards the end of theFU period when they were about to be treated" 
$\mathrm{CABG}=$ coronary artery bypass graft; $\mathrm{CCS}=$ Canadian Cardiovasclar Society; ECG = Electrocardiogram; FDA = Food and Drug Administration; $\mathrm{IQR}=$ interquartile range; NYHA = New York Heart Association; PTCA = percutaneous transluminal coronary angioplasty; $\mathrm{QOL}=$ quality of life; RCT = randomized controlled trial; TMLR = transmyocardial laser revascularization

\section{Characteristics of excluded studies [ordered by study ID]}

\begin{tabular}{|c|c|}
\hline Study & Reason for exclusion \\
\hline Allen 2000 & Comparison of TMLR combined with CABG versus CABG \\
\hline Appelman 1996 & No refractory angina patients. Comparison of laser angioplasty versus balloon angioplasty \\
\hline Appelman 1998 & No refractory angina patients. Comparison of laser angioplasty versus balloon angioplasty \\
\hline Appelman 2000 & No refractory angina patients. Comparison of laser angioplasty versus balloon angioplasty \\
\hline Dixon 2001 & Comparison of PTMR versus angioplasty combined with PTMR \\
\hline Dowling 2003 & $\begin{array}{l}\text { The objective was to prevent post-surgical pain, and surgical procedures were PTMR combined } \\
\text { with CABG versus CABG only }\end{array}$ \\
\hline Dziuk 2003 & Comparison of TMLR alone versus TMLR combined with CABG \\
\hline Frazier 2004 & Comparison of TMLR combined with CABG versus CABG \\
\hline Guleserian 2003 & $\begin{array}{l}\text { Comparison of TMLR versus TMLR combined with CABG. No random allocation of patients to treat- } \\
\text { ment groups }\end{array}$ \\
\hline Horvath, 2000a & Narrative overview of studies on TMLR \\
\hline Horvath, 2000b & Narrative overview of studies on TMLR \\
\hline Horvath, 2002 & Narrative overview of studies on TMLR \\
\hline Horvath, 2008 & Narrative overview of studies on TMLR \\
\hline Kniazeva 1994 & Laser procedure without thoracotomy \\
\hline Leon 2005 & $\begin{array}{l}\text { Results of PTMR instead of TMLR, and the control group was not receiving medical treatment, but } \\
\text { sham procedure }\end{array}$ \\
\hline Loubani 2003 & Comparison of CABG versus CABG combined with TMLR \\
\hline McNab 2006 & Comparison of spinal cord stimulation versus percutaneous laser myocardial revascularization \\
\hline Milano 1997 & Non-comparative study, reporting data only on TMLR treated patients \\
\hline Myers 2002 & Comparison of TMLR versus percutaneous laser myocardial revascularization \\
\hline Oesterle 1999 & Pilot study on percutaneous laser myocardial revascularization without medical treatment group \\
\hline Oesterle 2000 & Comparison of percutaneous laser myocardial revascularization versus medical treatment \\
\hline Salem 2004 & Comparison of percutaneous laser myocardial revascularization versus sham surgery \\
\hline Salem 2005 & Comparison of percutaneous laser myocardial revascularization versus sham surgery \\
\hline
\end{tabular}




\begin{tabular}{ll}
\hline Study & Reason for exclusion \\
\hline Salem 2006 & Comparison of percutaneous laser myocardial revascularization versus sham surgery \\
\hline Stone 2002 & Comparison of percutaneous laser myocardial revascularization versus medical treatment \\
\hline Vasil'ev 2003 & Non refractory angina patients. No randomisation \\
\hline Yang 2007 & $\begin{array}{l}\text { Comparison of percutaneous laser myocardial revascularization plus medical treatment versus } \\
\text { medical treatment alone }\end{array}$ \\
\hline
\end{tabular}

CABG = coronary artery bypass graft; PTCA = percutaneous transluminal coronary angioplasty; PTMR = Percutaneous myocardial revascularization; $T M L R=$ transmyocardial laser revascularization

\section{DATA AND ANALYSES}

\section{Comparison 1. Transmyocardial laser revascularization versus medical treatment}

\begin{tabular}{|c|c|c|c|c|}
\hline Outcome or subgroup title & $\begin{array}{l}\text { No. of } \\
\text { studies }\end{array}$ & $\begin{array}{l}\text { No. of } \\
\text { partici- } \\
\text { pants }\end{array}$ & Statistical method & Effect size \\
\hline 1 Angina reduction & 7 & 1051 & Odds Ratio (M-H, Fixed, 95\% Cl) & $4.63[3.43,6.25]$ \\
\hline 1.1 CCS score & 5 & 923 & Odds Ratio (M-H, Fixed, 95\% Cl) & $3.95[2.90,5.39]$ \\
\hline 1.2 NYHA scale & 2 & 128 & Odds Ratio (M-H, Fixed, 95\% Cl) & $68.32[7.95,587.38]$ \\
\hline 2 Angina reduction (as-treated) & 6 & 698 & Odds Ratio (M-H, Fixed, 95\% Cl) & $11.71[7.41,18.51]$ \\
\hline 3 Overall mortality & 7 & 1053 & Odds Ratio (M-H, Fixed, 95\% Cl) & $1.12[0.77,1.63]$ \\
\hline 4 Overall mortality (as-treated) & 7 & 1053 & Odds Ratio (M-H, Fixed, 95\% Cl) & $1.22[0.81,1.83]$ \\
\hline 5 Early post-operative mortality & 6 & 967 & Odds Ratio (M-H, Fixed, 95\% Cl) & $1.19[0.63,2.24]$ \\
\hline $\begin{array}{l}6 \text { Early post-operative mortality (as- } \\
\text { treated) }\end{array}$ & 7 & 1053 & Odds Ratio (M-H, Fixed, 95\% Cl) & $3.76[1.63,8.66]$ \\
\hline 7 Exercise tolerance & 2 & 129 & Mean Difference (IV, Fixed, 95\% CI) & $25.22[-35.28,85.72]$ \\
\hline $\begin{array}{l}8 \text { Seattle Angina Questionnaire - } \\
\text { physical limitation }\end{array}$ & 2 & 221 & Mean Difference (IV, Fixed, 95\% CI) & $13.10[6.82,19.38]$ \\
\hline $\begin{array}{l}9 \text { Seattle Angina Questionnaire - } \\
\text { angina frequency }\end{array}$ & 2 & 221 & Mean Difference (IV, Fixed, 95\% CI) & $-5.93[-12.49,0.63]$ \\
\hline $\begin{array}{l}10 \text { Seattle Angina Questionnaire - } \\
\text { quality of life }\end{array}$ & 2 & 221 & Mean Difference (IV, Fixed, 95\% CI) & $2.19[-4.64,9.03]$ \\
\hline
\end{tabular}


Analysis 1.1. Comparison 1 Transmyocardial laser revascularization versus medical treatment, Outcome 1 Angina reduction.

\begin{tabular}{|c|c|c|c|c|c|}
\hline Study or subgroup & $\begin{array}{c}\text { Favours } \\
\text { treatment } \\
\mathrm{n} / \mathrm{N} \\
\end{array}$ & Control & $\begin{array}{c}\text { Odds Ratio } \\
\text { M-H, Fixed, } 95 \% \mathrm{Cl}\end{array}$ & Weight & $\begin{array}{c}\text { Odds Ratio } \\
\text { M-H, Fixed, } 95 \% \mathrm{Cl}\end{array}$ \\
\hline \multicolumn{3}{|l|}{ 1.1.1 CCS score } & & & \\
\hline Allen 1999 & $58 / 132$ & $45 / 143$ & 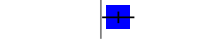 & $57.02 \%$ & $1.71[1.04,2.79]$ \\
\hline Burkhoff 1999 & $47 / 92$ & $8 / 90$ & $\longrightarrow$ & $9.31 \%$ & $10.71[4.65,24.63]$ \\
\hline Frazier 1999 & $44 / 91$ & $23 / 101$ & $\rightarrow-$ & $26.51 \%$ & $3.17[1.71,5.91]$ \\
\hline Schofield 1999 & $18 / 94$ & $3 / 94$ & $\longrightarrow$ & $5.71 \%$ & $7.18[2.04,25.32]$ \\
\hline Subtotal $(95 \% \mathrm{Cl})$ & 452 & 471 & 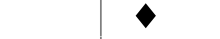 & $98.95 \%$ & $3.95[2.9,5.39]$ \\
\hline \multicolumn{6}{|c|}{ Total events: 196 (Favours treatment), 79 (Control) } \\
\hline \multicolumn{6}{|c|}{ Heterogeneity: Tau $^{2}=0 ; \mathrm{Chi}^{2}=24.79, \mathrm{df}=4(\mathrm{P}<0.0001) ; \mathrm{I}^{2}=83.86 \%$} \\
\hline \multicolumn{6}{|c|}{ Test for overall effect: $Z=8.67(P<0.0001)$} \\
\hline Aaberge 2000 & $19 / 49$ & $0 / 49$ & & $0.72 \%$ & $63.3[3.69,1086.76]$ \\
\hline van der Sloot 2004 & $11 / 15$ & $0 / 15$ & & $0.33 \%$ & $79.22[3.87,1622.84]$ \\
\hline Subtotal $(95 \% \mathrm{Cl})$ & 64 & 64 & & $1.05 \%$ & $68.32[7.95,587.38]$ \\
\hline \multicolumn{6}{|c|}{ Total events: 30 (Favours treatment), 0 (Control) } \\
\hline \multicolumn{6}{|c|}{ Heterogeneity: $\operatorname{Tau}^{2}=0 ; \mathrm{Chi}^{2}=0.01, \mathrm{df}=1(\mathrm{P}=0.91) ; \mathrm{I}^{2}=0 \%$} \\
\hline \multicolumn{6}{|c|}{ Test for overall effect: $Z=3.85(P=0)$} \\
\hline Total $(95 \% \mathrm{Cl})$ & 516 & 535 & $\diamond$ & $100 \%$ & $4.63[3.43,6.25]$ \\
\hline \multicolumn{6}{|c|}{ Total events: 226 (Favours treatment), 79 (Control) } \\
\hline \multicolumn{6}{|c|}{ Heterogeneity: $\mathrm{Tau}^{2}=0 ; \mathrm{Chi}^{2}=34.41, \mathrm{df}=6(\mathrm{P}<0.0001) ; \mathrm{I}^{2}=82.56 \%$} \\
\hline \multicolumn{6}{|c|}{ Test for overall effect: $Z=10(P<0.0001)$} \\
\hline Test for subgroup dif & $\mathrm{df}=1(\mathrm{P}=0.01), \mathrm{I}^{2}$ & & & & \\
\hline
\end{tabular}

$\begin{array}{lllllll}\text { Favours control } & 0.001 & 0.1 & 1 & 10 & 1000 & \text { Favours treatment }\end{array}$

Analysis 1.2. Comparison 1 Transmyocardial laser revascularization versus medical treatment, Outcome 2 Angina reduction (as-treated).

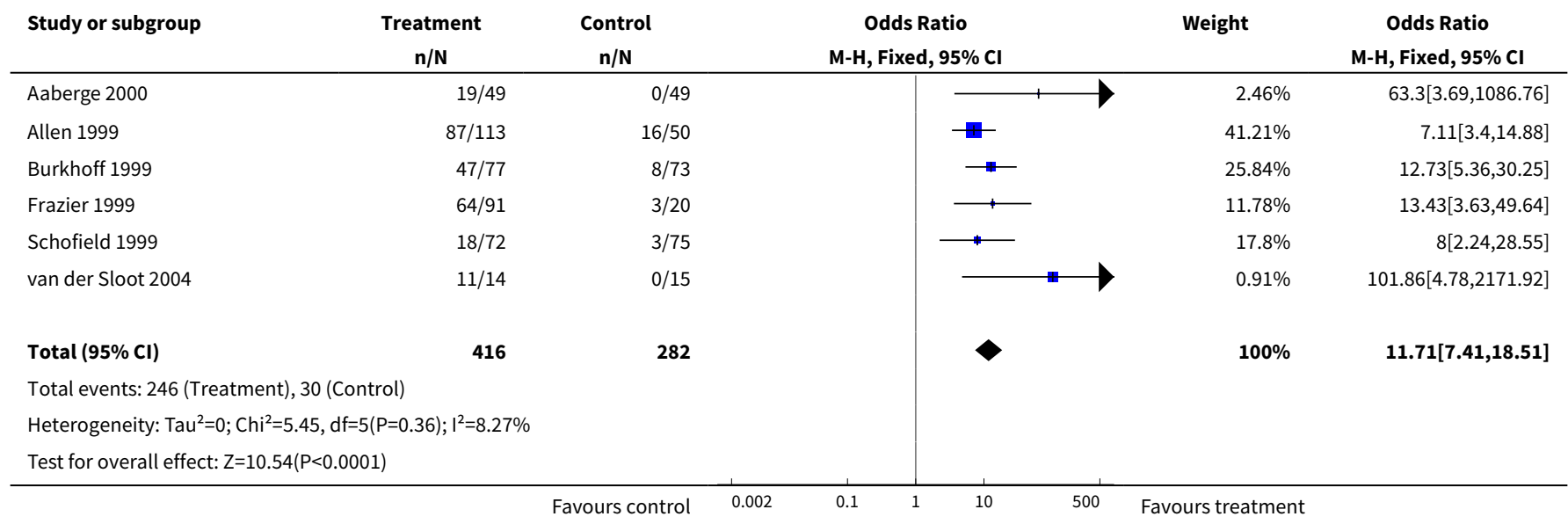


Analysis 1.3. Comparison 1 Transmyocardial laser revascularization versus medical treatment, Outcome 3 Overall mortality.

\begin{tabular}{|c|c|c|c|c|c|}
\hline Study or subgroup & $\begin{array}{c}\text { Treatment } \\
\mathrm{n} / \mathrm{N} \\
\end{array}$ & $\begin{array}{c}\text { Control } \\
n / N\end{array}$ & $\begin{array}{c}\text { Odds Ratio } \\
\text { M-H, Fixed, } 95 \% \mathrm{Cl}\end{array}$ & Weight & $\begin{array}{c}\text { Odds Ratio } \\
\text { M-H, Fixed, } 95 \% \mathrm{Cl}\end{array}$ \\
\hline Aaberge 2000 & $6 / 50$ & $4 / 50$ & $\longrightarrow *$ & $6.89 \%$ & $1.57[0.41,5.93]$ \\
\hline Allen 1999 & $21 / 132$ & $16 / 143$ & + & $25.28 \%$ & $1.5[0.75,3.02]$ \\
\hline Burkhoff 1999 & $5 / 92$ & $9 / 90$ & $\longrightarrow$ & $16.84 \%$ & $0.52[0.17,1.61]$ \\
\hline Frazier 1999 & $14 / 91$ & $22 / 101$ & $一$ & $34.54 \%$ & $0.65[0.31,1.37]$ \\
\hline van der Sloot 2004 & $1 / 15$ & $0 / 15$ & & $0.89 \%$ & $3.21[0.12,85.2]$ \\
\hline Jones 1999 & $5 / 43$ & $5 / 43$ & & $8.65 \%$ & $1[0.27,3.74]$ \\
\hline Total $(95 \% \mathrm{Cl})$ & 517 & 536 & & $100 \%$ & $1.12[0.77,1.63]$ \\
\hline \multicolumn{6}{|c|}{ Total events: 63 (Treatment), 60 (Control) } \\
\hline \multicolumn{6}{|c|}{ Heterogeneity: $\mathrm{Tau}^{2}=0 ; \mathrm{Chi}^{2}=7.81, \mathrm{df}=6(\mathrm{P}=0.25) ; \mathrm{I}^{2}=23.14 \%$} \\
\hline Test for overall effect & & & & & \\
\hline
\end{tabular}

Analysis 1.4. Comparison 1 Transmyocardial laser revascularization versus medical treatment, Outcome 4 Overall mortality (as-treated).

\begin{tabular}{|c|c|c|c|c|c|}
\hline Study or subgroup & $\begin{array}{c}\text { Treatment } \\
\mathrm{n} / \mathrm{N} \\
\end{array}$ & $\begin{array}{c}\text { Control } \\
\mathrm{n} / \mathrm{N}\end{array}$ & $\begin{array}{c}\text { Odds Ratio } \\
\text { M-H, Fixed, } 95 \% \mathrm{Cl}\end{array}$ & Weight & $\begin{array}{c}\text { Odds Ratio } \\
\text { M-H, Fixed, } 95 \% \mathrm{Cl}\end{array}$ \\
\hline Aaberge 2000 & $6 / 50$ & $4 / 50$ & $\longrightarrow$ & $8.23 \%$ & $1.57[0.41,5.93]$ \\
\hline Allen 1999 & $25 / 178$ & $12 / 97$ & & $31.22 \%$ & $1.16[0.55,2.42]$ \\
\hline Burkhoff 1999 & $5 / 92$ & $9 / 90$ & $\longrightarrow$ & $20.11 \%$ & $0.52[0.17,1.61]$ \\
\hline Frazier 1999 & $29 / 151$ & $7 / 41$ & $\longrightarrow$ & $20.8 \%$ & $1.15[0.47,2.86]$ \\
\hline Jones 1999 & $5 / 43$ & $5 / 43$ & & $10.33 \%$ & $1[0.27,3.74]$ \\
\hline van der Sloot 2004 & $1 / 15$ & $0 / 15$ & & $1.06 \%$ & $3.21[0.12,85.2]$ \\
\hline Total $(95 \% \mathrm{Cl})$ & 623 & 430 & & $100 \%$ & $1.22[0.81,1.83]$ \\
\hline \multicolumn{6}{|c|}{ Total events: 82 (Treatment), 41 (Control) } \\
\hline \multicolumn{6}{|c|}{ Heterogeneity: $\operatorname{Tau}^{2}=0 ; \mathrm{Chi}^{2}=4.98, \mathrm{df}=6(\mathrm{P}=0.55) ; \mathrm{I}^{2}=0 \%$} \\
\hline Test for overall effect & & & & & \\
\hline
\end{tabular}

Analysis 1.5. Comparison 1 Transmyocardial laser revascularization versus medical treatment, Outcome 5 Early post-operative mortality.

\begin{tabular}{|c|c|c|c|c|c|c|}
\hline Study or subgroup & $\begin{array}{c}\text { Treatment } \\
\mathrm{n} / \mathrm{N} \\
\end{array}$ & $\begin{array}{c}\text { Control } \\
n / N\end{array}$ & & $\begin{array}{c}\text { Odds Ratio } \\
\text { M-H, Fixed, } 95 \% \mathrm{Cl}\end{array}$ & Weight & $\begin{array}{c}\text { Odds Ratio } \\
\text { M-H, Fixed, } 95 \% \mathrm{Cl}\end{array}$ \\
\hline Aaberge 2000 & $2 / 50$ & $0 / 50$ & & 1 & $2.73 \%$ & $5.21[0.24,111.24]$ \\
\hline Allen 1999 & $7 / 132$ & $6 / 143$ & & $\longrightarrow$ & $31.29 \%$ & $1.28[0.42,3.91]$ \\
\hline Burkhoff 1999 & $1 / 92$ & $0 / 90$ & & & $2.85 \%$ & $2.97[0.12,73.8]$ \\
\hline Frazier 1999 & $3 / 91$ & $11 / 101$ & & 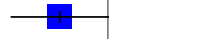 & $57.83 \%$ & $0.28[0.08,1.03]$ \\
\hline Schofield 1999 & $5 / 94$ & $0 / 94$ & & & $2.7 \%$ & $11.61[0.63,213.09]$ \\
\hline van der Sloot 2004 & $1 / 15$ & $0 / 15$ & & & $2.6 \%$ & $3.21[0.12,85.2]$ \\
\hline
\end{tabular}




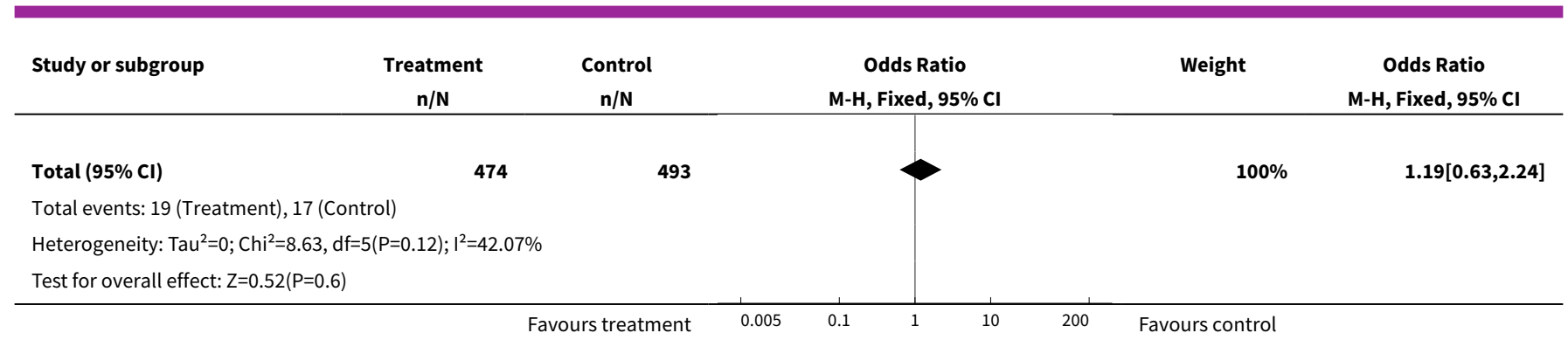

Analysis 1.6. Comparison 1 Transmyocardial laser revascularization versus medical treatment, Outcome 6 Early post-operative mortality (as-treated).

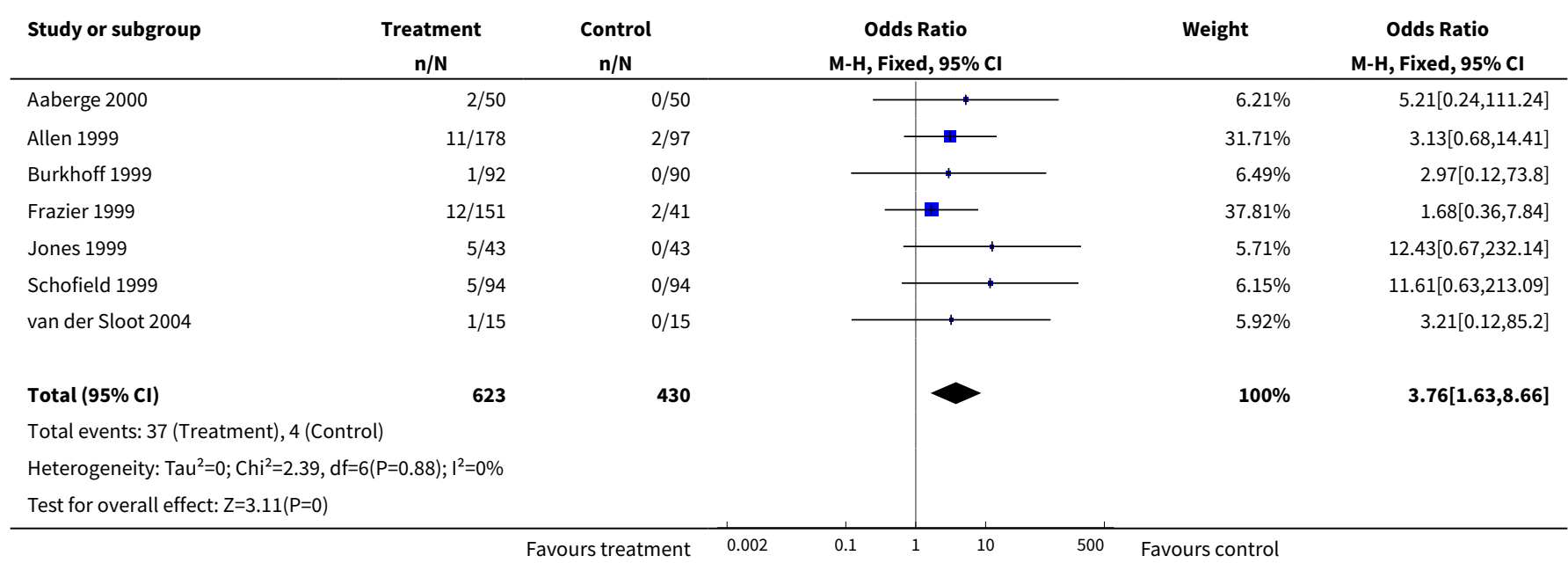

Analysis 1.7. Comparison 1 Transmyocardial laser revascularization versus medical treatment, Outcome 7 Exercise tolerance.

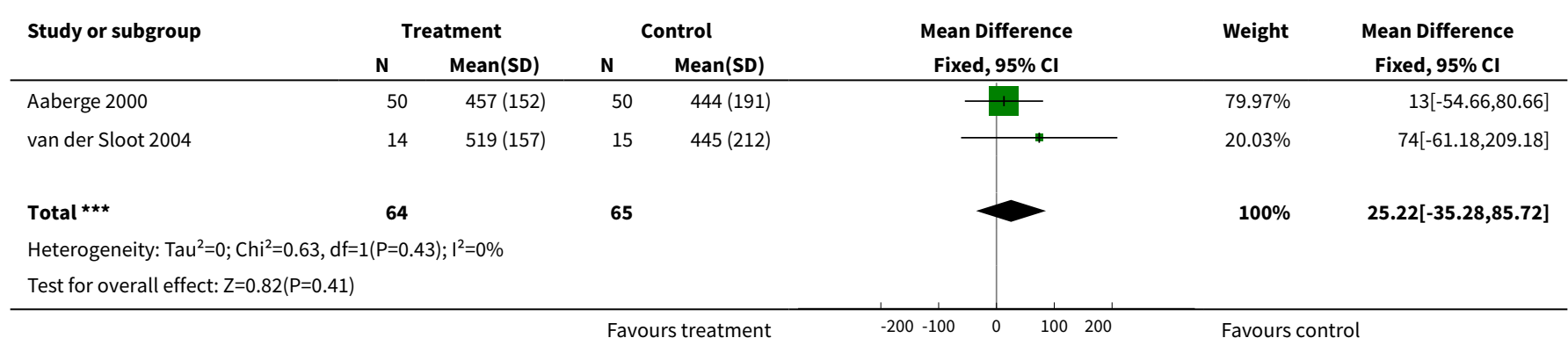


Analysis 1.8. Comparison 1 Transmyocardial laser revascularization versus medical treatment, Outcome 8 Seattle Angina Questionnaire - physical limitation.

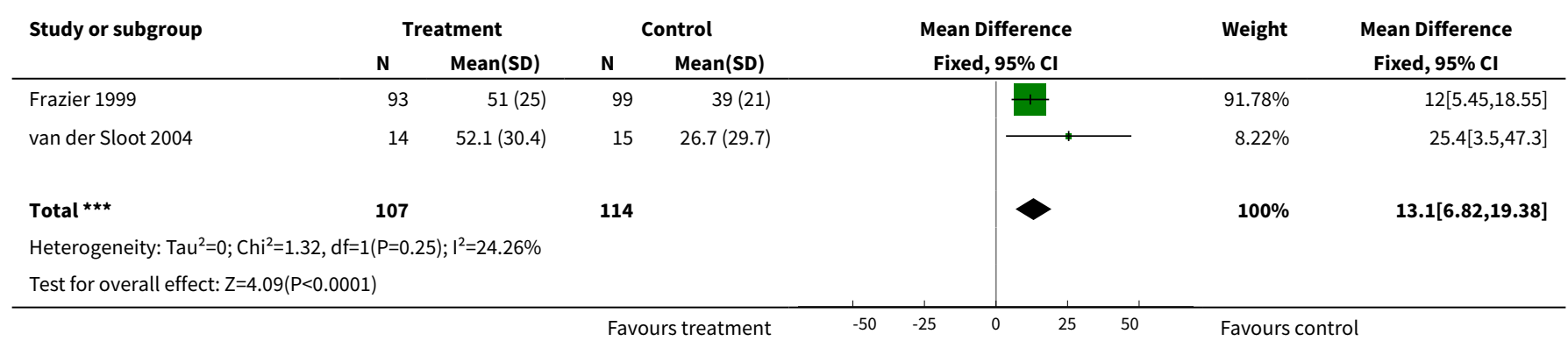

Analysis 1.9. Comparison 1 Transmyocardial laser revascularization versus medical treatment, Outcome 9 Seattle Angina Questionnaire - angina frequency.

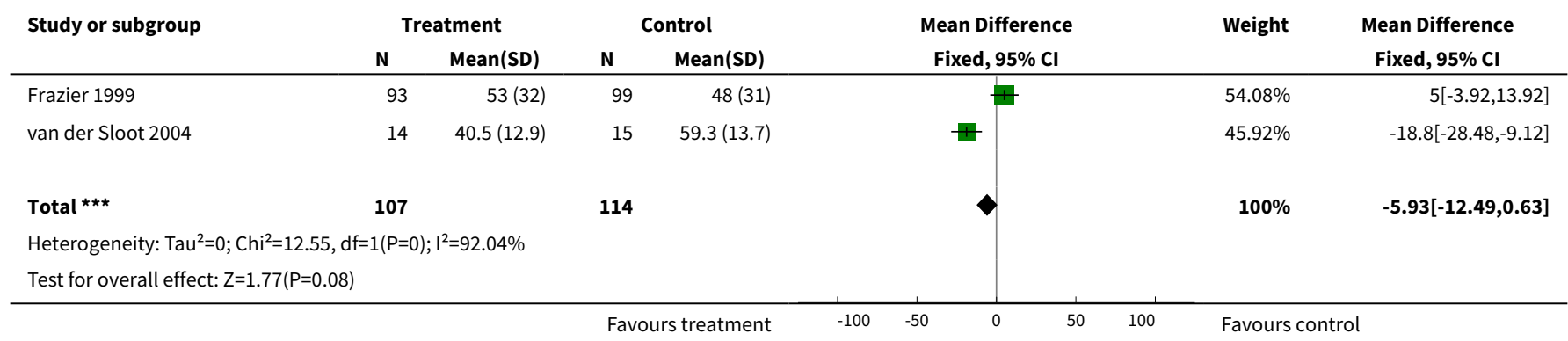

Analysis 1.10. Comparison 1 Transmyocardial laser revascularization versus medical treatment, Outcome 10 Seattle Angina Questionnaire - quality of life.

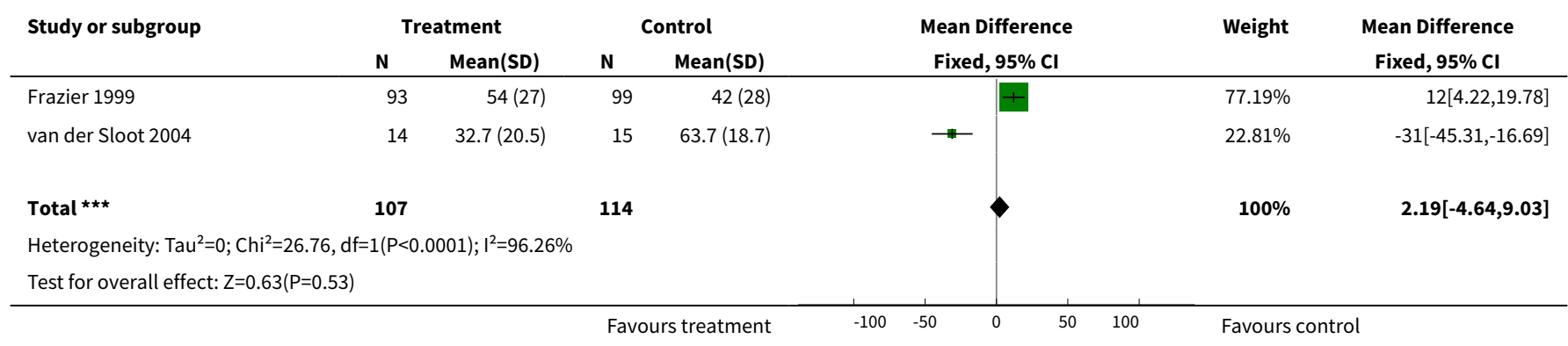

\section{ADDITIONAL TABLES}

Table 1. Primary and secondary outcomes, reported by authors

\begin{tabular}{lll}
\hline Study & Primary outcomes & Secondary outcomes \\
\hline Aaberge 2000 & $\begin{array}{l}\text { Time to one millimetre ST depression and } \\
\text { MVO2 }\end{array}$ & Time to chest pain, total exercise time and accumulated work \\
& & \\
\hline
\end{tabular}


Table 1. Primary and secondary outcomes, reported by authors (Continued)

\begin{tabular}{lll} 
Allen 1999 & $\begin{array}{l}\text { Change in angina symptoms, treatment } \\
\text { failure and change in myocardial perfu- } \\
\text { sion }\end{array}$ & $\begin{array}{l}\text { Freedom from cardiac-related hospitalization, survival free of car- } \\
\text { diac events, use of cardiac medications, performance on treadmill } \\
\text { test, and quality of life score }\end{array}$ \\
\hline Burkhoff 1999 & $\begin{array}{l}\text { Change in exercise duration on a stan- } \\
\text { dard protocol }\end{array}$ & Angina, quality of life, and dipyridamole thallium stress test \\
\hline Frazier 1999 & Not reported explicitly by the authors & Not reported explicitly by the authors \\
\hline Jones 1999 & Not reported explicitly by the authors & Not reported explicitly by the authors \\
\hline Schofield 1999 & $\begin{array}{l}\text { Duration of treadmill exercise test at 12- } \\
\text { months follow-up }\end{array}$ & $\begin{array}{l}\text { Left ventricular ejection fraction by radionuclide multigated ac- } \\
\text { quisition scan; chest pain perceived by patients. CCS score was not } \\
\text { part of the original trial protocol but included later }\end{array}$ \\
\hline van der Sloot 2004 & $\begin{array}{l}\text { Improvement of angina at 12-months fol- } \\
\text { low-up }\end{array}$ & $\begin{array}{l}\text { Medical treatment, clinical events, quality of life, exercise time, } \\
\text { and myocardial perfusion and function }\end{array}$ \\
\hline
\end{tabular}

\section{APPENDICES}

\section{Appendix 1. Search strategies 2014 \\ CENTRAL (The Cochrane Llbrary)}

Issue 6 of 12, June 2014. Search date: 11th June 2014 ( $N=91$ records)

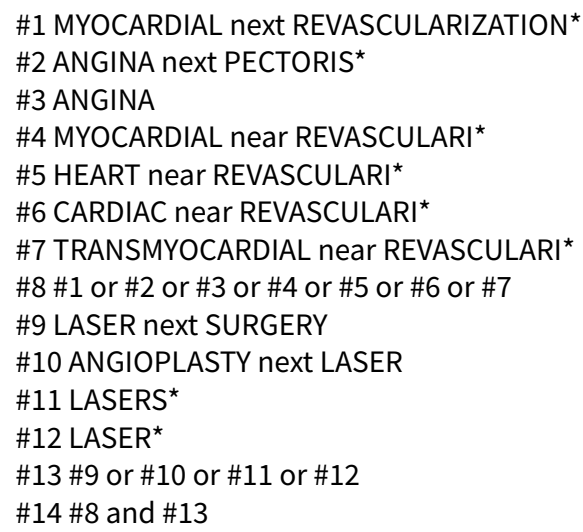

\section{MEDLINE (PubMed)}

(1946 to June Week 2 2014). Search date: 11th June 2014 ( $N=160$ records)

$(((((()(((()(((((" M y o c a r d i a l$ Revascularization"[MeSH Major Topic] $)))$ OR (("Angina Pectoris"[MeSH Major Topic]))) OR ((angina))) OR $\left(\left(\right.\right.$ myocardial near revasculari $\left.\left.\left.^{\star}\right)\right)\right)$ OR $\left(\left(\right.\right.$ heart near revasculari $\left.\left.\left.{ }^{\star}\right)\right)\right)$ OR ((cardiac near revasculari $\left.\left.)\right)\right)$ OR $\left(\left(\right.\right.$ transmyocardial near revasculari $\left.\left.\left.\left.{ }^{\star}\right)\right)\right)\right)$ AND $(((((((" L a s e r$ Surgery"[MeSH Major Topic]))) OR (("Angioplasty, Laser"[MeSH Major Topic]))) OR (("Lasers"[MeSH Major Topic]))) OR $\left(\left(\right.\right.$ lasers $\left.\left.\left.\left.\left.{ }^{\star}\right)\right)\right)\right)\right)$ AND ((clinical[Title/Abstract] AND trial[Title/Abstract]) OR clinical trials[MeSH Terms] OR clinical trial[Publication Type] OR random*[Title/Abstract] OR random allocation[MeSH Terms] OR therapeutic use[MeSH Subheading]) NOT (("Coronary Artery Bypass"[MeSH Major Topic]

\section{EMBASE (Ovid)}

(1980 to 2014 Week 23). Search date: 11th June 2014 ( $N=167$ records)

1 heart muscle revascularization/ (21752)

2 (myocardial adj3 revasculari\$).tw. (6704)

3 (heart adj3 revasculari\$).tw. (779) 
4 (cardiac adj3 revasculari\$).tw. (1018)

5 (transmyocardial adj3 revasculari\$).tw. (680)

6 exp Angina Pectoris/ (73730)

7 angina.tw. (54210)

8 or/1-7 (108113)

9 Laser Surgery/ (23158)

10 laser angioplasty/ (869)

11 exp laser/ (85517)

12 laser\$.tw. (178969)

13 or/9-12 (198152)

148 and 13 (1277)

15 clinical trial/ (831522)

16 random\$.tw. (873199)

17 randomized controlled trial/ (343012)

18 trial\$.tw. (794983)

19 follow-up.tw. (825154)

20 double blind procedure/ (113517)

21 placebo\$.tw. (197024)

22 placebo/ (240345)

23 factorial\$.ti,ab. (22736)

24 (crossover\$ or cross-over\$).ti,ab. (68317)

25 (double $\$$ adj blind\$).ti,ab. (140313)

26 (singl\$ adj blind\$).ti,ab. (14231)

27 assign\$.ti,ab. (235823)

28 allocat\$.ti,ab. (82510)

29 volunteer\$.ti,ab. (174246)

30 Crossover Procedure/ (39104)

31 Single Blind Procedure/ (18341)

32 or/15-31 (2874543)

33 exp animal/ (18627628)

34 nonhuman/ (4310562)

35 exp animal experiment/ (1674793)

36 or/33-35 (19829748)

37 exp human/ (14727333)

3836 not 37 (5102415)

3932 not $38(2635053)$

4039 and 14 (495)

41 limit 40 to $y r=" 2004$ - 2014" (167)

\section{ClinicalTrials.gov}

(http://www.clinicaltrials.gov/). Search date: 11th June 2014 (N=17)

1 revascularization AND laser

\section{metaRegister of Controlled Trials mRCT}

(http://www.controlled-trials.com/mrct). Search date: 11th June $2014(\mathrm{~N}=62)$

1 revascularization AND laser

\section{WHO International Clinical Trials Registry (ICTRP)}

(http://www.who.int/ictrp/search/en/). Search date: 11th June 2014 (N=5)

1 revascularization AND laser

\section{Appendix 2. Search strategies 2007}

\section{CENTRAL on The Cochrane Library}

The search was performed in the web "La Biblioteca Cochrane Plus" available from the Spanish Minitry of Health (http://www.updatesoftware.com/Clibplus/ClibPlus.asp).

\section{\#1 MYOCARDIAL next REVASCULARIZATION*} \#2 ANGINA next PECTORIS*

Transmyocardial laser revascularization versus medical therapy for refractory angina (Review) 
\#3 ANGINA

\#4 MYOCARDIAL near REVASCULARI *

\#5 HEART near REVASCULARI ${ }^{*}$

\#6 CARDIAC near REVASCULARI*

\#7 TRANSMYOCARDIAL near REVASCULARI*

\#8 \#1 or \#2 or \#3 or \#4 or \#5 or \#6 or \#7

\#9 LASER next SURGERY

\#10 ANGIOPLASTY next LASER

\#11 LASERS*

\#12 LASER*

\#13 \#9 or \#10 or \#11 or \#12

$\# 14$ \#8 and \#13

\section{MEDLINE}

$(((((()((((()((((($ "Myocardial Revascularization"[MeSH Major Topic] $))))$ OR (("Angina Pectoris"[MeSH Major Topic] $)))$ OR ((angina))) OR $\left(\left(\right.\right.$ myocardial near revasculari $\left.\left.\left.^{\star}\right)\right)\right)$ OR $\left(\left(\right.\right.$ heart near revasculari $\left.\left.\left.{ }^{\star}\right)\right)\right)$ OR ((cardiac near revasculari $\left.\left.\left.{ }^{\star}\right)\right)\right)$ OR ((transmyocardial near revasculari $\left.\left.\left.\left.{ }^{\star}\right)\right)\right)\right)$ AND $(((((((" L a s e r$ Surgery"[MeSH Major Topic]))) OR (("Angioplasty, Laser"[MeSH Major Topic]))) OR (("Lasers"[MeSH Major Topic]))) OR $\left(\left(\right.\right.$ lasers $\left.\left.\left.\left.\left.{ }^{\star}\right)\right)\right)\right)\right)$ AND ((clinical[Title/Abstract] AND trial[Title/Abstract]) OR clinical trials[MeSH Terms] OR clinical trial[Publication Type] OR random*[Title/Abstract] OR random allocation[MeSH Terms] OR therapeutic use[MeSH Subheading]) AND "1997/03/14 01.45" : "2007/03/14 01.45"[PDat]))) NOT (("Coronary Artery Bypass"[MeSH Major Topic] AND "1997/03/14 01.45" : "2007/03/14

\section{EMBASE}

1 heart muscle revascularization/ (10008)

2 (myocardial adj3 revasculari\$).tw. (3027)

3 (heart adj3 revasculari\$).tw. (248)

4 (cardiac adj3 revasculari\$).tw. (358)

5 (transmyocardial adj3 revasculari\$).tw. (456)

6 exp Angina Pectoris/ (34927)

7 angina.tw. (27834)

8 or/1-7 (52088)

9 Laser Surgery/ (12756)

10 laser angioplasty/ (525)

11 exp laser/ (34582)

12 laser\$.tw. (76994)

13 or/9-12 (84847)

148 and 13 (787)

15 clinical trial/ (426483)

16 random\$.tw. (337348)

17 randomized controlled trial/ (119040)

18 trial\$.tw. (296752)

19 follow-up.tw. (306510)

20 double blind procedure/ (64157)

21 placebo\$.tw. (98580)

22 placebo/ (99069)

23 factorial\$.ti,ab. (6886)

24 (crossover\$ or cross-over\$).ti,ab. (35815)

25 (double\$ adj blind\$).ti,ab. (77323)

26 (singl\$ adj blind\$).ti,ab. (6660)

27 assign\$.ti,ab. (94832)

28 allocat\$.ti,ab. (29752)

29 volunteer $\$$.ti,ab. (89976)

30 Crossover Procedure/ (18704)

31 Single Blind Procedure/ (6639)

32 or/15-31 (1205353)

33 exp animal/ (113406)

34 nonhuman/ (2891884)

35 exp animal experiment/ (1184729)

36 or/33-35 (3131158)

37 exp human/ (5761289)

3836 not 37 (2679515)

3932 not 38 (1108623) 
4039 and 14 (312)

41 limit 40 to $y r=" 2004-2007 "(62)$

42 from 41 keep 1-62 (62)

\section{WHAT'S NEW}

\begin{tabular}{lll}
\hline Date & Event & Description \\
\hline 12 April 2016 & Review declared as stable & No new trials since 2004 and no known ongoing trials. \\
\hline
\end{tabular}

\section{H I S T O R Y}

Protocol first published: Issue 3, 2002

Review first published: Issue 1, 2009

\begin{tabular}{lll}
\hline Date & Event & Description \\
\hline 19 June 2014 & $\begin{array}{l}\text { New citation required but conclusions } \\
\text { have not changed }\end{array}$ & $\begin{array}{l}\text { New search run and no new studies found for inclusion; there- } \\
\text { fore there are no changes to the conclusions. }\end{array}$ \\
\hline 19 June 2014 & New search has been performed & $\begin{array}{l}\text { We added a new author and included 'Risk of bias' tables and a } \\
\text { 'Summary of findings' table. We also added a 'Risk of bias' graph } \\
\text { and 'Risk of bias' summary figure. }\end{array}$ \\
\hline 7 August 2008 & Amended & Converted to new review format. \\
\hline
\end{tabular}

\section{CONTRIBUTIONS OF AUTHORS}

Eduardo Briones (EB): previous work, conceived the study, co-ordinated the preparation of the protocol, read and selected abstracts and papers, interpreted results, and drafted the review.

Juan Ramon Lacalle (JRL): developed and performed the search strategy and data collection, preparation of the protocol, analyzed data, and contributed to drafting the review.

Ignacio Marin-Leon (IM): previous work, conceived the study, checked the search results, critically revised the manuscript, and provided a clinical and policy perspective.

José-Ramón Rueda (JRR): updated the searches and extracted data for assessment of risks of bias, and contributed to drafting the update of the review.

All authors approved the final version.

\section{DECLARATIONS OF INTEREST}

None known.

\section{SOURCES OF SUPPORT}

\section{Internal sources}

- Andalusian Agency for Health Technology Assessment, Spain.

- University of Seville, Spain.

- Andalusian Health Service, Spain.

\section{External sources}

- No sources of support supplied 


\section{N D EX TERMS}

\section{Medical Subject Headings (MeSH)}

Angina Pectoris [mortality] [*therapy]; Laser Therapy [adverse effects] [ ${ }^{\star}$ methods] [mortality]; Myocardial Revascularization [adverse effects] [*methods] [mortality]; Randomized Controlled Trials as Topic; Thoracotomy

\section{MeSH check words}

Humans 